Canadian

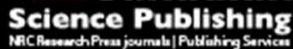

Canadian Geotechnical Journal Revue canadienne de géotechnique

\title{
Brittle fracture of rock under combined tensile and compressive loading conditions
}

\begin{tabular}{|r|l|}
\hline Journal: & Canadian Geotechnical Journal \\
\hline Manuscript ID & cgj-2016-0214.R1 \\
\hline Manuscript Type: & Article \\
\hline Date Submitted by the Author: & 21-Aug-2016 \\
\hline Complete List of Authors: & $\begin{array}{l}\text { Tang, Shibin; Dalian University of Technology, School of Civil Engineering } \\
\text { Bao, C.Y.; Shaoxing University, College of Civil Engineering } \\
\text { Liu, H.Y.; University of Tasmania, School of Engineering and ICT }\end{array}$ \\
\hline Keyword: & brittle fracture, crack initiation, fracture mechanics, T-stress \\
\hline & \multicolumn{2}{l}{} \\
\hline
\end{tabular}

SCHOLARONE ${ }^{\text {IM }}$

Manuscripts 


\title{
Brittle fracture of rock under combined tensile and compressive loading
}

\section{conditions}

\author{
S. B. Tang ${ }^{\mathrm{a}, 1}$, C. Y. Bao ${ }^{\mathrm{b}}$, H.Y. Liu ${ }^{\mathrm{c}}$ \\ ${ }^{a}$ State Key Laboratory of Coastal and Offshore Engineering, Dalian 116024, China \\ ${ }^{b}$ College of Civil Engineering, Shaoxing University, Shaoxing 312000, China \\ ${ }^{c}$ School of Engineering and ICT, The University of Tasmania, Hobart TAS7001, Australia
}

\begin{abstract}
The brittle fracture of rock with an angled crack under combined tensile and compressive loading conditions is studied using linear elastic fracture mechanics (LEFM). The modified maximum tangential stress criterion (MTSC) and the maximum shear stress criterion (MSSC) are used to check crack initiations in the tensile and shear modes, respectively. The effects of the friction coefficient of the crack surfaces and the non-singular stresses ( $T$-stresses) on the crack initiation are studied for the cases of both low and high compressive confining pressure coefficients.
\end{abstract} The $T$-stresses include those both parallel $\left(T_{x}\right)$ and perpendicular $\left(T_{y}\right)$ to the crack plane. The type of crack initiation under the combined tensile and compressive loading conditions is found to remain tensile dominated when the compressive confining pressure coefficient is small. However, shear crack extension becomes possible with the compressive confining pressure coefficient and friction coefficient increasing if the crack orientation angle is small. Moreover, the high compressive confining pressure and substantial friction are found to increase the possibility of

\footnotetext{
${ }^{1}$ Corresponding author Tel: +86 411 84708694; Email address: Tang_shibin@dlut.edu.cn
} 
shear crack extension. The theoretical predictions presented in this study move one step forward than the available analytical solutions for the angled crack subjected to general bi-axial load and agree well with those from experimental tests.

Keywords: brittle fracture; crack initiation; fracture mechanics; $T$-stress 


\section{NOMENCLATURE}

\begin{tabular}{|c|c|}
\hline$T_{x}, T_{y}$ & Horizontal and vertical non-singular stresses \\
\hline$A_{1}, A_{2}, A_{3}$ & Coefficients defined in Eq. (1) \\
\hline CIA & Crack initiation angle \\
\hline CIS & Crack initiation stress \\
\hline$k$ & Biaxial loading ratio \\
\hline$K_{\mathrm{I}}, K_{\mathrm{II}}$ & Stress intensity factors of mode I and mode II \\
\hline$r_{\mathrm{c}}$ & Critical radius at the crack tip \\
\hline$\alpha$ & Normalize critical radius defined in Eq. (15) \\
\hline$\beta$ & Crack orientation angle (COA) \\
\hline$\beta_{0}$ & Critical value of the crack orientation angle \\
\hline$\theta_{\mathrm{c}}$ & Crack initiation angle \\
\hline$\theta, r$ & Polar coordinates originating at the crack tip \\
\hline$\mu$ & Friction coefficient \\
\hline$\sigma_{\mathrm{c}}$ & Crack initiation stress in tension \\
\hline$\sigma_{i j}$ & Stress at the crack tip \\
\hline$\sigma_{r}, \sigma_{\theta}, \sigma_{r \theta}$ & Radial, tangential and shear stresses in polar coordinates \\
\hline$\sigma_{x}, \sigma_{y}, \tau_{x y}$ & Stresses around the crack tip in Cartesian coordinates \\
\hline$\sigma_{n}$ & Normal stress on the crack surface \\
\hline$\sigma_{0}$ & Fracture stress \\
\hline$\tau_{c}$ & Crack initiation stress in shear \\
\hline$\tau_{f}$ & Frictional shear stress on crack surface \\
\hline
\end{tabular}


$\tau_{\text {eff }} \quad$ Effective shear stress on crack surface

$\tau_{n t} \quad$ Shear stress on crack surface induced by external loads 


\section{Introduction}

Crack initiation and growth in brittle materials under either tensile or compressive loads have been extensively investigated using analytical, experimental and numerical methods (Aliha et al. 2012; Amarasiri et al. 2011; Bakuckas et al. 1993; Broberg 1987; Castro et al. 2016; Eftis and Subramonian 1978; Erarslan and Williams 2013; Funatsu et al. 2014; Mirsayar 2014; Park and Bobet 2009; Wu and Wong 2012; Wu and Wong 2013; Xeidakis et al. 1997). However, relatively little is known about cracking phenomena in brittle materials such as rock under combined tensile and compressive loads. Many important engineering applications, including hydraulic fracturing, landslide and gas outbursts in mining, involve in cracking and failure caused by combined tensile and compressive loads. For example, during the construction of a hydropower station, the rock along high-steepness slopes is initially under multi-axial compression before excavation, which results in pre-existing cracks being closed, as shown in Fig. 1 (when the pressure $p=0$ ). The excavation causes significant unloading, which results in pre-existing cracks gradually opening. Groundwater subsequently fills in the cracks, which results in the pre-existing cracks being subjected to not only compressive but also tensile loads, as shown in Fig. 1 (where the pressure $p>0$ ). This type of stress state transition is observed in coal mining engineering, where the pressure $p$ in this case is caused by both gas and water. The combined tensile and compressive loading condition is simplified as Fig. 2, where the lateral pressure coefficient is $k \leq 0$. 
To study the crack growth in brittle materials under the combined tensile and compressive loading conditions, LEFM is broadly used to predict the crack propagation path according to the crack initiation angle (CIA) $\theta_{\mathrm{c}}$. Chang (1982) studied the CIA and crack initiation stress (CIS, $\sigma_{\mathrm{c}}$ ) under biaxial loading conditions, including combined tensile and compressive loads in which the maximum compressive load was ten-times larger than the tensile load. Under such a condition, the crack face would most likely be closed, resulting in $K_{\mathrm{I}}=0$ and the friction on the crack face influencing crack initiation. However, this consideration was neglected in Chang's (1982) study. In another of Chang's (1981) studies, it was noted that the displacements of the crack faces tended to overlap each other in a certain range of the crack orientation angle (COA, $\beta)$ under the combined tensile and compressive loading conditions, which indicates that the predictions based on the maximum stress criterion should not be valid. Khan and Khraisheh (2000) studied mixed mode CIAs in rocks under various loading conditions, in which the combined tensile and compressive loads were specified by the biaxial ratios of $k=-0.5$ and -1.0 . They concluded that, when $k=-0.5$, the signs of both normal $\left(\sigma_{\mathrm{n}}\right)$ and shear $\left(\tau_{\mathrm{nt}}\right)$ stresses became positive after $\beta \geq 35^{\circ}$. The transition between the tensile and compressive behaviors of cracks occurred at $\beta=45^{\circ}$ when $k=-1.0$. However, under such loading conditions, they did not consider the contact behavior between the crack faces because they only considered the initial extension angles of the open cracks. Eftis and Subramonian (1978) studied the combined effects of load biaxiality and crack orientation on $K_{\mathrm{I}}, K_{\mathrm{II}}$ and the angle of initial crack extension. Although they examined the maximum shear stress at the 
crack tip, they did not study the shear crack extension under combined tensile and compressive stresses, and the friction on the crack faces was also neglected for a closed crack. Papadopoulos (1988) proposed a criterion, which stated that the crack propagated in the direction of the maximum value of the determinant of the stress tensor. Based on this criterion, he studied the CIA and CIS for the cracks under biaxial loading conditions, including the combined tensile and compressive loading conditions. However, his study neglected the effects of contact and friction on the crack extensional characteristics. Other studies on the effects of biaxial loading conditions, including the combined tensile and compressive loading conditions, have been conducted by Liebowitz et al. (1978), Theocaris and Michopoulos (1983), Shetty et al. (1987), and Zeng and Dai (1994), Shlyannikov (2013), Ge et al. (2014), Kannusamy and Ramesh (2014), and Meek and Ainsworth (2015).

The literature reviews above show that the crack growth in rocks under the combined tensile and compressive loading conditions requires further study in order to understand its mechanism, particularly the transition of the stress states between tension and compression on the crack faces, the resistance of friction to slide, and the situation concerning tensile and shear crack initiations. In general, it is understood that the slipping on the crack faces under shear stress results in tensile (wing) crack growth at the tip of the crack. Such a mechanism of slipping zone propagation in cracks and traction changes due to crack propagation have been studied both analytically (Martel and Pollard 1989; Palmer and Rice 1973) and experimentally 
(Bouissou et al. 1998; Dieterich 1981; Lee and Ravichandran 2003). However, most of these studies have not focused on shear crack initiation with considering the contact condition on the crack faces taken into account.

This paper presents an analytical study of crack initiation in brittle rock under the combined tensile-compressive quasi-static loading conditions, with particular attention being paid to the frictional characteristics of the microcracks as well as the influence of various physical parameters governing the crack initiation. The theoretical background of the stress distribution and crack extension criteria for brittle rocks under tensile and compressive loads are first reviewed in Sections "stress field near the crack tip and the fracture criterion" and "crack extension criteria", respectively. The analytical results of the crack extension characteristics in brittle rocks are then presented in Section "crack initiation under combined tensile and compressive loads". Finally, the findings from this study are summarized in Section “conclusions".

\section{Stress field near the crack tip and the fracture criterion}

In the present analyses, all stress components are calculated based on the exact elastic stress solutions of an infinite rock plate under the loading configuration depicted in Fig. 2. The lateral pressure coefficient is defined as $k \leq 0$. The crack is oriented at an angle $\beta$ (inclination angle) measured clockwise from the direction of the vertical load. Crack initiation is assumed to occur at an angle $\theta_{\mathrm{c}}$, also measured clockwise. The 
length of the crack is $2 a$. All the criteria that we are going to analyze depend on the stress field existing immediately before the onset of crack propagation. If $r$ and $\theta$ are defined as those in Fig. 3, the stress field at the crack tip in Cartesian coordinates can be described by Williams' expression in Eq. 1 (Williams 1957):

$$
\sigma_{i j}=A_{1} r^{-1 / 2} f_{i j}^{1}(\theta)+A_{2} f_{i j}^{2}+A_{3} r^{1 / 2} f_{i j}^{3}(\theta)+\cdots
$$

where $r$ and $\theta$ are the radius and angle, respectively, in polar coordinates, which originate at the crack tip and follow the line of the crack extension. If the numerical constants are absorbed into the non-dimensional $f_{i j}^{n}$ terms in Eq. $1, A_{1}$ can be identified as $K_{\mathrm{I}}$ or $K_{\mathrm{II}}$. The uniform and non-singular stress $A_{2}$ directly applies to all planes normal to the crack line (Leevers and Radon 1982). The last term in Eq. 1 is a high-order term.

In 1966, Cotterell (1966) concluded that the second term in Eq. 1 had a significant effect on the crack initiation direction even under simple tension. After that, many studies further indicated that the second term significantly affects the crack extension characteristics of brittle solids (Aliha and Saghafi 2013; Erdogan and Sih 1963; Finnie and Saith 1973; Larsson and Carlsson 1973; Smith et al. 2001; Williams and Ewing 1972). In general, the non-singular term is called the $T$-stress, which is parallel to the crack and is independent of the radius $r$. Ayatollahi et al. (2002a) observed that the tangential stress along the direction of maximum tangential stress increased with positive $T$ increasing but decreased with negative $T$. When the $T$-stress exceeded a critical value, the maximum tangential stress was no longer along the line of the initial 
crack, which caused a deviation in the initiation angle of the fracture. The larger the $T$-stress, the greater the deviation, which in turn caused a reduction in apparent fracture toughness. Roychowdhury and Dodds (2004) and Aliha et al. (2013) suggested that the $T$-stress strongly affected the crack initiation angle, the crack tip constraint, the shape and size of the plastic zone ahead of the crack tip, the crack closure, and the crack growth rate. Moreover, Mirlohi and Aliha (2013) studied the crack growth path for an angled cracked plate using higher order terms of the Williams series expansion, which confirmed the importance of including the T-stress for predicting crack trajectories. However, because they only focused on the biaxial tension loading condition, the $T_{y}$-stress was not included in their study.

When a crack in rocks is subjected to tension, the non-singular term in Williams' Eq. 1 only contains the stress parallel to the crack. However, if the crack is closed as shown in Fig. 4, the non-singular term includes another non-singular stress perpendicular to the crack and equal to the contact stress on the crack faces (i.e., $\sigma_{n}$ ). Furthermore, for a closed crack, the frictional shear stress, which opposes the sliding along the crack faces, is related to the pressure on the crack face through the Coulomb friction law:

$$
\tau_{f}=\mu \sigma_{n}
$$

where $\mu$ is the frictional coefficient and $\sigma_{n}<0$ is the contact stress for the compression state of the crack. 
When the shear stress on the crack surfaces is smaller than the frictional force, the crack is in the sticking state. Otherwise, the crack is in the slipping state. For any crack extension, the frictional resistance on the crack surfaces must be overcome, i.e., the crack must be in the slipping state. This study mainly focuses on the crack extension, i.e. the crack is in the slipping state. For the plates with a central crack shown in Fig. 2, the shear stress along the crack surface is greater than zero for $0^{\circ} \leq \beta$ $\leq 90^{\circ}$. The normal stress on the crack surface is smaller than zero if the crack is in the closed state. Therefore, the effective shear stress $\tau_{\text {eff }}$ on the crack surfaces in a centrally cracked plate can be written as Eq. (3)

$$
\tau_{e f f}=\tau_{n t}+\tau_{f}
$$

where $\tau_{n t}$ is the shear stress induced by external loads. Note that the direction of the friction stress $\tau_{f}$ (negative) is always opposite to that of the shear stress $\tau_{n t}$ (positive).

The above discussion shows that, for an open crack, the stress at the crack tip contains the singular stress terms defined by $K_{\mathrm{I}}, K_{\mathrm{II}}$ and $T$-stress, which is parallel to the crack and is denoted as $T_{x}$. For a closed crack, the parameter $K_{\mathrm{I}}=0$. However, an additional non-singular stress term, defined as $T_{y}$ in this study, must be included. Therefore, the stress field around the crack tip in this case is given by Eq. 4 :

$$
\left\{\begin{array}{l}
\sigma_{x}=\frac{K_{I}}{\sqrt{2 \pi r}} \cos \frac{\theta}{2}\left(1-\sin \frac{\theta}{2} \sin \frac{3 \theta}{2}\right)-\frac{K_{I I}}{\sqrt{2 \pi r}} \sin \frac{\theta}{2}\left(2+\cos \frac{\theta}{2} \cos \frac{3 \theta}{2}\right)+T_{x} \\
\sigma_{y}=\frac{K_{I}}{\sqrt{2 \pi r}} \cos \frac{\theta}{2}\left(1+\sin \frac{\theta}{2} \sin \frac{3 \theta}{2}\right)+\frac{K_{I I}}{\sqrt{2 \pi r}} \sin \frac{\theta}{2} \cos \frac{\theta}{2} \cos \frac{3 \theta}{2}+T_{y} \\
\tau_{x y}=\frac{K_{I}}{\sqrt{2 \pi r}} \cos \frac{\theta}{2} \sin \frac{\theta}{2} \cos \frac{3 \theta}{2}+\frac{K_{I I}}{\sqrt{2 \pi r}} \cos \frac{\theta}{2}\left(1-\sin \frac{\theta}{2} \cos \frac{3 \theta}{2}\right)
\end{array}\right.
$$

where $K_{I I}=\tau_{\text {eff }} \sqrt{\pi a}$. Note that $T_{y}=0$ when $\sigma_{n}>0$, and $T_{y}=\sigma_{n}$ when $\sigma_{n} \leq 0$. 
Correspondingly, the stress distribution at the crack tip in the polar co-ordinate system shown in Fig. 3 is

$$
\left\{\begin{array}{l}
\sigma_{\mathrm{r}}=\frac{1}{2 \sqrt{2 \pi r}}\left[K_{I} \cos \frac{\theta}{2}(3-\cos \theta)+K_{I I} \sin \frac{\theta}{2}(3 \cos \theta-1)\right]+T_{x} \cos ^{2} \theta+T_{y} \sin ^{2} \theta \\
\sigma_{\theta}=\frac{1}{2 \sqrt{2 \pi r}} \cos \frac{\theta}{2}\left[K_{I}(1+\cos \theta)-3 K_{I I} \sin \theta\right]+T_{x} \sin ^{2} \theta+T_{y} \cos ^{2} \theta \\
\tau_{r} \theta=\frac{1}{2 \sqrt{2 \pi r}} \cos \frac{\theta}{2}\left[K_{I} \sin \theta+K_{I I}(3 \cos \theta-1)\right]-\left(T_{x}-T_{y}\right) \sin \theta \cos \theta
\end{array}\right.
$$

The stresses in the local $t$ - $n$ coordinate system shown in Fig. 2 are

$$
\left\{\begin{array}{l}
\sigma_{n}=\sigma[(1+k)-(1-k) \cos 2 \beta] / 2 \\
\sigma_{t}=\sigma[(1+k)+(1-k) \cos 2 \beta] / 2 \\
\tau_{n t}=\sigma(1-k) \sin 2 \beta / 2
\end{array}\right.
$$

where $k \leq 0$.

If $\sigma_{n} \geq 0$, the crack is in the open state, suggesting that there is no friction on the crack face. Then, the parameters $K_{\mathrm{I}}, K_{\mathrm{II}}, T_{x}$ and $T_{y}$ in Fig. 2 can be defined as

$$
\left\{\begin{array}{l}
K_{I}=\sigma_{n} \sqrt{\pi a} \\
K_{I I}=\tau_{n t} \sqrt{\pi a} \\
T_{x}=\sigma_{t}-\sigma_{n}=\sigma(1-k) \cos 2 \beta \\
T_{y}=0
\end{array}\right.
$$

However, if $\sigma_{n} \leq 0$, the crack is in the closed state, indicating that there is friction on the crack faces. Then, the parameters $K_{\mathrm{I}}, K_{\mathrm{II}}, T_{x}$ and $T_{y}$ in Fig. 2 can be defined as

$$
\left\{\begin{array}{l}
K_{I}=0 \\
K_{I I}=\tau_{\text {eff }} \sqrt{\pi a} \\
T_{x}=\sigma_{t}=\sigma[(1+k)+(1-k) \cos 2 \beta] / 2 \\
T_{y}=\sigma_{n}=\sigma[(1+k)-(1-k) \cos 2 \beta] / 2
\end{array}\right.
$$


Li et al. (2009) investigated the role of the $T_{\mathrm{y}}$ component on crack growth. However, they did not study the effects of the crack orientation angle and confining pressure ratio on the crack growth. Eqs. (6)-(8) show that both the crack orientation angle and the confining pressure ratio are included in the $T_{x}$ and $T_{\mathrm{y}}$ components. Moreover, note that the $T_{x}$ terms for the cracks in the tensile $\left(\sigma_{n} \geq 0\right)$ and compressive $\left(\sigma_{n}<0\right)$ states are different, as clearly observed from Eqs. (7) and (8).

In this study, the fracture parameters shown in Eq. (7) and Eq. (9) can be directly obtained using LEFM for a centrally cracked plate. However, for specimens with more complex geometries, such as the centrally cracked Brazilian disc (CCBD) and semi-circular bends (SCBs), the parameters must be determined using numerical methods (Aliha and Ayatollahi 2009, 2013; Aliha et al. 2008; Ayatollahi and Aliha 2007). Ayatollahi et al. (1998) proposed displacement-based and stress-based methods for evaluating the $T_{x}$-stress under mixed-mode I/II loading, which indicated that the displacement-based method was more precise than the stress-based method. However, few researchers have discussed the numerical calculation of $T_{y}$-stresses for closed cracks which requires further studies

\section{Crack extension criteria}

One cannot predict the direction and path of crack propagation in rocks without crack initiation criterion (or fracture criterion), which is required to judge whether a crack 
initiates or propagates under a certain loading condition. Several crack initiation criteria have been proposed. Among them, the maximum tangential stress (MTS), maximum tangential principal stress (MTPS), minimum strain energy density (SED), maximum energy release rate (MERR), maximum stress triaxiality (MST), local symmetry (LS) and critical distances (CD) criteria became popular and were implemented in many studies (Castro et al. 2016; Gupta et al. 2015; Kong et al. 1995; Maiti and Smith 1983; Mróz and Mróz 2010; Smith et al. 2001; Zanganeh et al. 2008). A detailed summary of these criteria was provided by Khan and Khraisheh (2000). For tensile cracking, the MTS criterion is the simplest one and is widely used. The MTS criterion states that the direction of the crack initiation coincides with the direction of the maximum tangential stress along a constant radius around the crack tip. In general, the MTS criterion provides accurate results for tensile fracture in most brittle materials, including rock. The crack initiation direction $\theta_{\mathrm{c}}$ according to the MTS criterion can be found from the conditions specified in Eq. 9:

$$
\sigma_{\theta}>0, \frac{\partial \sigma_{\theta}}{\partial \theta}=0, \frac{\partial^{2} \sigma_{\theta}}{\partial \theta^{2}}<0
$$

By substituting the stress field in Eq. 5 into the MTS criterion in Eq. 9, we obtain the following equations:

$$
\left\{\begin{array}{l}
\cos \frac{\theta_{c}}{2}\left[K_{I}\left(1+\cos \theta_{c}\right)-3 K_{I I} \sin \theta_{c}\right]+2 T_{x} \sqrt{2 \pi r_{c}} \sin ^{2} \theta_{c}+2 T_{y} \sqrt{2 \pi r_{c}} \cos ^{2} \theta_{c}>0 \\
3 \cos \frac{\theta}{2}\left[K_{I} \sin \theta+K_{I I}(3 \cos \theta-1)\right]-4 \sqrt{2 \pi r_{c}}\left(T_{x}-T_{y}\right) \sin 2 \theta_{c}=0 \\
3 \sin \frac{\theta}{2}\left[K_{I} \sin \theta+K_{I I}(3 \cos \theta-1)\right]-6 \cos \frac{\theta}{2}\left[K_{I} \cos \theta-3 K_{I I} \sin \theta\right]+32 \sqrt{2 \pi r_{c}}\left(T_{x}-T_{y}\right) \cos 2 \theta_{c}<0
\end{array}\right.
$$

where $r_{\mathrm{c}}$ is an additional length scale representing the size of the fracture process zone (Kim and Paulino 2003). 
Eq. 10 is called the generalized MTS criterion (GMTS), which was defined by Smith et al. (2001). Once the crack initiation angle $\theta_{\mathrm{c}}$ is determined, the crack initiation condition is obtained by considering the critical tangential stress $\left(\sigma_{\theta}\right)_{c}$ at a distance $r_{\mathrm{c}}$, which is expressed in Eq. 11:

$$
\sqrt{2 \pi r_{c}}\left(\sigma_{\theta}\right)_{c}=\cos \frac{\theta_{c}}{2}\left[K_{I} \cos ^{2} \frac{\theta_{c}}{2}-\frac{3}{2} K_{I I} \sin \theta_{c}\right]+T_{x} \sqrt{2 \pi r_{c}} \sin ^{2} \theta_{c}+T_{y} \sqrt{2 \pi r_{c}} \cos ^{2} \theta_{c}(11)
$$

where $\left(\sigma_{\theta}\right)_{c}$ equals $\sigma_{\mathrm{c}}$, which is the critical value of the tensile strength of rock.

Many studies (e.g., Williams and Ewing (1972); Ayatollahi et al. (2002b); and Smith et al. (2001)) reported that the predictions of tensile crack initiation using the maximum tangential stress criterion including the $T$ stress were in good agreement with the results of experimental tests and might be further improved when the tangential stress wascomputed at a certain distance from the crack tip. However, most of the fracture criteria, including the MTS criterion, are only suitable for the case where the stress intensity factor of mode $\mathrm{I}$ is greater than zero, i.e., $K_{\mathrm{P}}>0$. For compressive cracks, when the term related to $K_{\mathrm{I}}$ does not appear, a new criterion is needed. Note that the crack extension in rock is complicated by the mix-mode fractures observed in experiments, which indicate that the rock may fail via two distinct macroscopic fracture types, i.e., the opening type (tensile crack) and the shear type (shear crack). Bobet (2000) experimentally observed shear crack initiation occurring simultaneously with tensile crack initiation. Many other studies (e.g., Wong and Chau (1998), Wong and Einstein (2009), and Park and Bobet (2009)) indicated 
that the secondary crack was a type of shear crack. Melin (1986), Isaksson and Ståhle (2002) and Labuz et al. (2006), indicated that cracks in rock could propagate in shear when the compressive load was sufficiently high. Therefore, if a crack is under the combined tensile and compressive loads, the high compressive load may cause the crack to close, resulting in the shear stress at the crack being much larger than the tensile stress. In 1975, Otsuka et al. (1975) proposed a shear stress approach for studying shear fracture that assumed that a crack might grow via the mode-II mechanism on the plane of the maximum shear stress. Based on this criterion, Bordi et al. (1998) proposed a finite element model to predict crack initiation and propagation in a notched disk subjected to rolling contact fatigue. Bakuckas et al. (1993), Seweryn and Mróz (1995), Chao and Liu (1997), and Shamoto and Altıntas (1999) used the maximum shear stress criterion (MSSC) to study the crack growth characteristics of many materials, including rock. In particular, Bobet et al. (Bobet 2000; Bobet and Einstein 1998; Vásárhelyi and Bobet 2000) used MSSC to predict the crack initiation angle and stress in rock and suggested that this criterion was able to capture the basic behavior of the shear cracking process observed in experiments. According to MSSC, a shear crack initiates in rock when the shear stress $\left|\tau_{r \theta}\right|$ reaches the critical shear strength of the rock (i.e., $\tau_{c}$ ), i.e.,

$$
\left|\tau_{r \theta}\right| \geq \tau_{c}
$$

According to the selected MTSC and MSSC criteria, crack initiation may occur in either tensile or shear orboth tensile and shear modes, depending on the stress states at 
the crack tip, i.e.,

(1) if $\left(\sigma_{\theta}\right)_{\max }<\sigma_{\mathrm{c}}$ and $\left|\tau_{r \theta}\right|_{\max }<\tau_{\mathrm{c}}$, no cracking is initiated;

(2) if $\left(\sigma_{\theta}\right)_{\max } \geq \sigma_{\mathrm{c}}$ and $\left|\tau_{r \theta}\right|_{\max }<\tau_{\mathrm{c}}$, tensile cracking is initiated;

(3) if $\left(\sigma_{\theta}\right)_{\max }<\sigma_{\mathrm{c}}$ and $\left|\tau_{r \theta}\right|_{\max } \geq \tau_{\mathrm{c}}$, shear cracking is initiated;

(4) if $\left(\sigma_{\theta}\right)_{\max } \geq \sigma_{\mathrm{c}}$ and $\left|\tau_{r \theta}\right|_{\max } \geq \tau_{\mathrm{c}}$, both tensile and shear cracking are initiated.

Both the maximum tangential and shear stress criteria implemented in this study are based on the assumption that the crack initiation in rock depends on the local stress states relative to the strength of the rock rather than the stress intensity factors (SIFs). This is ascertained by comparing the theoretical predictions using these criteria with the crack initiation stress and direction and the crack coalescence stress and type obtained from experiments in the literature.

\section{Crack initiation under combined tensile and compressive loads}

\section{Transition between open and closed cracks}

Eq. 6 shows that the normal stress on the crack face may be negative or positive, depending on the confining pressure coefficient $k$ and the crack orientation angle $\beta$. Fig. 5(a) shows the relationship between the normalized $\sigma_{n}$ and $\beta$. Note that, under uniaxial tension, the normal stress on the crack face is always greater than zero, which forms an open crack. However, when the compressive confining pressure coefficient is not zero, the normal stress is negative at first but then gradually changes to positive with increasing $\beta$. The transition of $\sigma_{n}$ from negative to positive values indicates that 
the crack state changes from the closed to open state. The critical value of $\beta_{0}$ where $\sigma_{n}$ changes sign can be calculated using Eq. 13:

$$
\beta_{0}=\arctan \sqrt{-k}
$$

Fig. 5(b) depicts the relationship between $\beta_{0}$ and $k$. Note that the critical value $\beta_{0}$ increases with increasing absolute confining pressure coefficient. However, regardless of how the confining pressure coefficient increases, there is a certain range of the crack orientation angle where $\sigma_{n}$ remains positive. If $k \rightarrow-\infty$, the condition is close to the uniaxial compressive stress state. Clearly, the friction on the crack face, when $\sigma_{n}<0$, plays an important role in the mechanical behavior of the crack, which will be further discussed in the following sections.

\section{Effective shear stress on the crack face}

The relationships between normalized $\tau_{e f f}$ and $\beta$ for different confining pressure coefficients are shown in Fig. 6, where the solid lines indicate the effective shear stress $\left(\tau_{e f f}\right)$ on the crack face for the closed crack calculated using Eq. 3, while the dotted lines are the shear stress for the open crack $\left(\sigma_{n}>0\right)$ calculated using Eq. 6. Fig. 6(a) shows that $\tau_{\text {eff }}$ increases with increasing crack orientation angle at first, except for in the region of the blank length where the sliding on the crack face is inhibited by the friction stress, and the effective shear stress is $\tau_{\text {eff }}=0$. The larger the confining pressure coefficient, the greater the rate of increase. However, when the crack orientation angle increases to a certain value, $\tau_{\text {eff }}$ begins to decrease with increasing 
crack orientation angle and finally reaches zero at $\beta=90^{\circ}$. There is an angle at which the transition from the closed to open states by the crack occurs for each confining pressure coefficient, i.e., the angle corresponding to the transitional point from the solid to dashed lines in Fig. 6, which can also be observed in Fig. 5(b). The range of $\beta$ in which the crack faces become closed also increases with increasing compressive confining pressure coefficient. The comparison between the friction coefficients $\mu=0.2$ (Fig. 6(a)) and 0.5 (Fig. 6(b)) shows that the transition angle between the closed and open states of the crack face is not affected by the friction coefficient. However, the increasing rate of the effective stress on the crack face increases with the friction coefficient increasing. Furthermore, both Fig. 6(a) and (b) show that the range of crack orientation angle where $\tau_{\text {eff }}=0$ increases with the increasing of both the confining pressure and the friction coefficient. Fig. 6(b) shows the blank length of $L_{1}$, $L_{2}$ and $L_{3}$ when the confining pressure coefficient is $k=-0.25,-0.5$ and -1.0 , respectively. The critical angle $\beta$ where $\tau_{e f f}=0$ can be calculated from

$$
(1-k) \sin 2 \beta+\mu[(1+k)-(1-k) \cos 2 \beta]=0
$$

\section{Stress distribution around the crack tip}

Eq. 5 shows that the stress distribution around the crack tip depends on $K_{\mathrm{I}}, K_{\mathrm{II}}, T_{x}, T_{y}$ and the radius $r$, in which $K_{\mathrm{I}}, K_{\mathrm{II}}, T_{x}$ and $T_{y}$ can be determined using Eq. 7 or Eq. 8 for the given confining pressure coefficient $k$, crack orientation angle $\beta$ and friction coefficient $\mu$. The radius $r$ is an important parameter that determines the stress magnitude around the crack tip. The critical radius $r_{\mathrm{c}}$ in Eq. 10 is often considered as a 
material constant in rock (Ayatollahi and Aliha 2008). Many studies have suggested that $r_{\mathrm{c}}$ is a function of uniaxial tensile strength $\left(\sigma_{c}\right)$ and mode-I fracture toughness $\left(K_{I C}\right)$ (Golos and Wasiluk 2000; Irwin 1958; Rice 1967; Schmidt 1981). To normalize the critical radius $r_{c}$, we assume that

$$
\alpha=\sqrt{2 r_{c} / a}
$$

According to Williams and Ewing (1972) and Smith et al. (2006), the non-dimensional length $\alpha$ is a fitted parameter that provides the best prediction consistent with experiment. In this section, all the results are obtained by assuming $\alpha=0.1$ according to Erdogan and Sih (1963), Williams and Ewing (1972) and Ling (1980).

When the "singular solution" is used to represent the crack tip stress, one may incorrectly think there is no biaxial load effect for a horizontal crack (Eftis and Subramonian 1978). However, Fig. 7 shows that the stress distributions of both $\sigma_{\theta}$ and $\tau_{r \theta}$ around the crack tip strongly vary with increasing $|k|$. When $|k|$ is smaller than 1.0, both $\sigma_{\theta}$ and $\tau_{r \theta}$ are not significantly affected by the $T$ stress, although the maximum $\sigma_{\theta^{-}} T$ and $\left|\tau_{r \theta^{-}} T\right|$ are slightly greater than $\sigma_{\theta}$ and $\left|\tau_{r \theta}\right|$. However, when $k=-10$, the maximum $\sigma_{\theta}-T$ is obviously smaller than $\sigma_{\theta}$. Instead, for the maximum absolute shear stress, $\left|\tau_{r \theta}-T\right|$ is greater than $\left|\tau_{r \theta}\right|$. Furthermore, the critical crack inclination angles $\beta$, where $\sigma_{\theta^{-}} T$ and $\sigma_{\theta}$ or $\left|\tau_{r \theta^{-}} T\right|$ and $\left|\tau_{r \theta}\right|$ obtain their maximum values, vary with increasing $|k|$ as well. The difference, caused by whether the $T$ stress is considered, 
becomes much greater when the confining pressure coefficient is high such as when $k=-100$. In sum, the results show that the consideration of $T$ stress decreases the tangential stress but increases the shear stress. Moreover, it is important to note that $\left|\tau_{r \theta}\right|_{\max } / \sigma_{\theta, \max }$ is a constant value of 0.866 when the $T$ stress is neglected. However, when the $T$ stress is included in Eq. 5, $\left|\tau_{r \theta}\right|_{\max } / \sigma_{\theta, \max }$ varies with increasing $|k|$. The results above show that when $k=-10,\left|\tau_{r \theta}\right|_{\max } / \sigma_{\theta, \max }$ is approximately equal to 1.100 , which, in contrast, is 1.585 when $k=-100$ and 1.740 when $k \rightarrow-\infty$. Therefore, the $T$ stress promotes shear crack extension at the crack tip.

Fig. 8 shows the stress distribution around the crack tip when the crack inclination angle varies if the confining pressure coefficient and the friction coefficient are held constant, i.e., $k=-0.5$ and $\mu=0.5$. Note that when $\beta=15^{\circ}$, there is a significant difference between either the circumferential or radial stresses regardless of whether the $T$ stress is considered. However, this difference is not obvious when $\beta \geq 30^{\circ}$. Eq. 13 shows that, when $\beta \leq 35.26^{\circ}$, the crack faces are closed at $k=-0.5$. Therefore, the friction plays an important role in the stress distribution at the crack tip. This is why the ratio between $\left(\sigma_{\theta}-T\right)_{\max }$ and $\sigma_{\theta, \max }$ is much greater when $\beta=15^{\circ}$ than that when $\beta>30^{\circ}$. For an open crack, the friction is neglected, and the parameter $\beta$ does not significantly affect the stress distribution at the crack tip.

Most studies on the $T$ stress have focused on mode-I loading, i.e., the crack was subjected to far-field tensile loads in both $x$ and $y$ directions. However, the growth of a 
closed crack under compression is more common in rock engineering. The friction on the crack faces significantly affects the stress distribution at the crack tip, as shown in Fig. 9, where a crack with an orientation of $\beta=30^{\circ}$ is subjected to far-field tensile-compressive loads. The critical crack orientation angles, where the transition between the tensile and compressive states of the crack face occurs, i.e., $\sigma_{n}=0$, are $45^{\circ}$ and $65.9^{\circ}$ when $k=-1$ and -5 , respectively. Therefore, for $\beta=30^{\circ}$, the crack faces can be closed under both conditions of $k=-1$ and -5 . Moreover, Fig. 9 shows that the $T$ stress does not significantly affect the stress distribution for both lower $(\mu=0.2)$ and higher $(\mu=0.7)$ friction coefficients if $|k|$ is small. However, when the crack is subjected to a high compressive confining pressure, the stress at the crack tip strongly varies from lower to higher friction coefficients. For example, when $k=-5$ and $\mu=0.2$, the effect of the $T$ stress on the stress distribution at the crack tip is not obvious. However, when the friction coefficient is increasing, the difference caused by whether the $T$ stress is considered continuously increases. Furthermore, $\left|\tau_{r \theta}\right|_{\max }$ is smaller than $\sigma_{\theta, \max }$ when the frictional coefficient of the crack faces is smaller. However, they change when $\mu$ is large. The result in Fig. 9 shows that $\left|\tau_{r \theta}\right|_{\max }$ is 2.2-times larger than $\sigma_{\theta, \max }$ when $\mu=0.7$ if the $T$ stress is included in the stress distribution at the crack tip. This means that the friction promotes shear crack extension under the high compressive confining pressure.

In addition, Fig. 6 shows that $\tau_{e f f}=0$ indicates that the cracks cannot slide along the crack faces. Under such a condition, both the stress intensity factors $K_{I}$ and $K_{I I}$ are 
zero, and the singular stress disappears. Thus, the failure can no longer be estimated by the fracture mechanics approach. The failure is instead analyzed using the jointed rock method developed based on Mohr-Coulomb fracture theory (Jaeger and Cook 1979). The actual shear failure surface is usually observed to have an orientation angle of $\theta_{\mathrm{c}}=\pi / 4+\phi / 2$ from the plane where the maximum compressive principal stress is applied, in which $\phi$ is the slope of the failure envelope and, in the particular Coulomb case, $\phi$ is equal to the internal friction angle of the rock.

\section{Tensile crack initiation}

When the far-field tensile load is larger than the compressive load $(-1 \leq k \leq 0)$, the tensile stress at the crack tip is larger than the shear stress, except that, for a small crack orientation angle, the crack cannot slip, which is denoted as the blank length in Fig. 6. In this section, only the tensile crack initiation characteristic is analyzed while that of the shear crack is to be discussed in Section "shear crack initiation".

\section{Crack initiation angle}

Fig. 10 shows the relationship between the crack initiation angle $\left(\theta_{c}\right)$ and the crack orientation angle $(\beta)$ under uniaxial tension and its comparison with corresponding experimental data obtained by Ling (1980) and Ueda et al. (1983). Note that the predicted $\theta_{c}$ is in good agreement with that obtained by experiments when the non-dimensional length $\alpha$ is 0.1 or 0.2 . However, when $\alpha=0$, the second equation in Eq. (10) shows that the $T$ stress is neglected, and the predicted $\theta_{c}$ is the classical 
solution, which does not agree well with experimental data. For a small crack orientation angle, the predicted $\theta_{c}$ from the classical solution of $\alpha=0$ is smaller than that of the experiments, whereas for a large crack orientation angle, the predicted $\theta_{c}$ for $\alpha=0$ is larger than that of the experiments. The crack growth under uniaxial tension has been broadly discussed before, and representative studies were conducted by Maiti and Smith (1983), Papadopoulos (1988), Smith et al. (2001), and Kim and Paulino (2003).

Fig. 11 shows the relationship between the crack initiation angle and the crack orientation angle under combined tensile and compressive loads. The relationships for the case of the friction coefficient $\mu=0.5$ were also experimentally determined by Ling (1980), which are plotted in Fig. 11. It can be seen from the comparisons between the theoretical prediction and experimental test that the results for $\alpha=0.1$ best fit the PMMA experimental data, especially when the crack is closed. Moreover, in order to study the effect of the friction on the crack initiation, the relationship between the crack initiation angle and the crack orientation angle for the case of $\mu=0$ is plot in Fig. 11. As the crack orientation angle changes from $0^{\circ}$ to $90^{\circ}$, the crack initiation can be classified into two regions, i.e., the initiations of closed and open cracks. In Fig. 11, the initiation of the closed crack is plotted using dashed lines, and that of the open crack is plotted using solid lines. When the compressive confining pressure is low, the crack initiation angles at the transition points for different $\alpha$ are quite different, which can be clearly observed in the enlarged graphs on the right-hand of Fig. 11(a). 
However, the crack initiation angles at the transition points gradually converge to the same value with the compressive confining pressure coefficient increasing, as shown in Fig. 11 when $k=-1.0$. Furthermore, when $\beta=45^{\circ}$ and $0 \leq k \leq 1$, the crack is open, and both the $T_{x}$ and $T_{y}$ stresses are zero. Therefore, the crack initiation angle is independent of the non-dimensional length $\alpha$. In other words, all the crack initiation angles are equal for different values of $\alpha$ when $\beta=45^{\circ}$. For an open crack, $\theta_{c}$ decreases with increasing $\alpha$ when $\beta>45^{\circ}$ and vice-versa when $\beta<45^{\circ}$, as observed from the solid lines in Fig. 11. For a closed crack, $\theta_{c}$ is not only dependent on the parameters $\beta$ and $k$ but also significantly affected by $\mu$ and $\alpha$, as shown by the dashed lines in Fig. 11. Moreover, it is noted that the friction on the crack faces shifts toward high crack initiation angles. If the $T$ stress and the closed states are neglected when the normal stress $\sigma_{n}<0$, the classic solution of $\theta_{c}$ is a constant value equal to $70.5^{\circ}$ regardless of how the parameters $\beta$ and $k$ vary. The consideration of the $T$ stress is found to be very important for the evaluation of the crack growth direction, especially for closed cracks with large friction on the surfaces.

Because the contact behavior of the crack faces under compression is not considered, Eftis and Subramonian (1978) predicted the angle of the initial crack extension to be greater than $90^{\circ}$ when $\beta<28^{\circ}$ and $k=-2$ or $\beta<21^{\circ}$ and $k=-1$. However, both the experimental data and the predicted results depicted in Fig. 11 show that there is no (or shouldn't have) $\theta_{\mathrm{c}}$ greater than $90^{\circ}$. The calculation of the crack initiation angle conducted by Eftis and Subramonian (1978) included both $K_{I}$ and $K_{I I}$ even when $K_{I}<0$, i.e., the parameter $K_{I}$ also existed for the closed crack. However, according to 
classical fracture mechanics, $K_{I}$ is always larger than or at least equal to zero. Furthermore, Eftis and Subramonian (1978) did not consider the friction on the faces of closed cracks. In this study, the opening and closing conditions of the crack, the friction on the faces of the closed crack and the $T_{x}$ and $T_{y}$ stresses are included in the evaluation of the crack initiation direction, which is more reasonable and accurate compared with the studies conducted by Eftis and Subramonian (1978). Moreover, the theoretical results are calibrated based on experiments available in the literature (Ling 1980).

\section{Tensile crack initiation stress}

To calculate the crack initiation stress (i.e. the so-called fracture stress, $\sigma_{0}$ ), the non-dimensional length $\alpha$ must first be determined. According to the results concerning the crack initiation angle in Fig. 10, the parameter $\alpha$ is set as 0.1 in this study. Fig. 12 shows the fracture stresses of a crack with various orientation angles under combined tensile and compressive loads. The experimental data from the literature (Ling 1980) are also plotted in Fig. 12 for comparison, which shows that the predicted result is in good agreement with the experimental result under the uniaxial tensile load. If the compressive confining pressure coefficient increases to -0.25 , the crack faces contact with each other when $\beta<26.56^{\circ}$. Moreover, the fracture stresses obtained for the frictional $(\mu=0.5)$ and frictionless $(\mu=0)$ crack faces are found to be highly different from each other, and the failure stress for the frictional crack is larger than that for the frictionless crack with the same orientation angle as that of the 
friction crack. The larger the compressive confining pressure coefficient is, the greater the difference, which is more clearly observed when $k=-0.5$ and -1.0 . Due to the effect of friction on the fracture stress, the experimental data are more scattered than are those in the case of open cracks, which can be clearly observed when $k=-0.5$ and -1.0 . However, the theoretical curves are clearly in good agreement with the experimental results. Furthermore, the results also reveal that the fracture stress is not obviously affected by the compressive confine pressure coefficient when the crack is in the open state, as shown by the black curves in Fig. 12. However, if the fracture is dominated by the far-field compressive stress, the fracture stress is substantially different for the different confining pressure coefficients in the case of the frictional crack, as observed from the red curves before the compressive-tensile transition point in Fig. 12. Moreover, in all cases for $-1 \leq k \leq 0$, the fracture stress increases as the crack orientation angle decreases.

More significantly, Fig. 12 also shows that if the crack is in the contact state, the fracture stress versus $\beta$ curves becomes steeper and narrower as $\mu$ increases, which reveals that the range of the crack orientation angle, in which the crack surfaces cannot slide against each other and in which shear failure is the only possible mode, increases with the friction coefficient increasing. A crack with an orientation angle in that range can no longer slide because of the constraint effect of the friction, which can also be observed from the blank length in Fig. 6. Therefore, although cracks with orientation angles that fall in a wide range are able to grow in the tensile mode at a 
stress slightly above the minimum initiation stress in the case of $\mu=0$, only the cracks with orientation angles in a narrow range can grow in the tensile mode when $\mu$ is high. Moreover, the particular tendency whereby the failure stress of cracks with small orientation angles $\beta$ increases with increasing friction coefficient $\mu$ should be noted, where the cracks are subjected to not only a small resolved shear stress but also a large resolved compressive normal stress if the compressive confining pressure is sufficiently large.

\section{Shear crack initiation}

Fig. 13(a) shows the ratio between the absolute maximum shear stress $\left(\left|\tau_{r \theta}\right|_{\max }\right)$ and the maximum tangential stress $\left(\left(\sigma_{\theta}\right)_{\max }\right)$ for different friction coefficients when $\beta=25^{\circ}$. Note that if the crack faces have a small friction coefficient, $\left|\tau_{r \theta}\right|_{\max }$ is smaller than $\left(\sigma_{\theta}\right)_{\max }$. However, with increasing friction coefficient, $\left|\tau_{r \theta}\right|_{\max } /\left(\sigma_{\theta}\right)_{\max }$ gradually increases with increasing compressive confining pressure coefficient. The greater confining pressure coefficient suggests a larger ratio between $\left|\tau_{r \theta}\right|_{\max }$ and $\left(\sigma_{\theta}\right)_{\max }$. Fig. 13(b) shows that, with increasing $\beta$, the compressive confining pressure coefficient must also be increased to obtain the same ratio of $\left|\tau_{r \theta}\right|_{\max } /\left(\sigma_{\theta}\right)_{\max }$. For example, to satisfy $\left|\tau_{r \theta}\right|_{\max } /\left(\sigma_{\theta}\right)_{\max } \geq 2.0, k$ only needs to be greater than -2.93 when $\beta=20^{\circ}$. However, $k$ increases to -7.78 when $\beta=25^{\circ}$. Moreover, there is no value of $k$ satisfying $\left|\tau_{r \theta}\right|_{\max } /\left(\sigma_{\theta}\right)_{\max } \geq 2.0$ if $\beta \geq 30^{\circ}$. Specifically, shear crack initiation is impossible at a large crack orientation angle when the crack is under far-field tensile-compressive loading. For a ratio between shear and tensile strength $\left(\tau_{\mathrm{c}} / \sigma_{\mathrm{c}}\right)$ of 2.0, Fig. 13(b) shows the 
relationship between $\beta$ and $k$, which satisfies $\left|\tau_{r \theta}\right|_{\max } /\left(\sigma_{\theta}\right)_{\max }=2$ when $\mu=0.5$. The zones above and below the solid line are the shear and tensile crack initiation zones, respectively. Note that different ratios of the shear and tensile $\tau_{\mathrm{c}} / \sigma_{\mathrm{c}}$ lead to different sizes of the shear and tensile crack initiation zones; however, the law is similar. This result suggests that the growth in shear cracks most likely occurs under high confining pressure, as confirmed by Melin (1986). Furthermore, for a given $k$ and $\beta$, both $\left|\tau_{r \theta}\right|_{\max }$ and $\left(\sigma_{\theta}\right)_{\max }$ decrease with increasing friction on the crack faces; however, the ratio of $\left|\tau_{r \theta}\right|_{\max } /\left(\sigma_{\theta}\right)_{\max }$ increases, which suggests that the greater friction also causes shear crack initiation when the crack is in the closed state. Fig. 13(c) shows the relationship between the confining pressure coefficient and the critical friction coefficient for shear crack initiation and indicates that the critical friction coefficient leading to shear crack initiation decreased with increasing compressive confining pressure coefficient. The results reveal that, in addition to the condition of high compressive confining pressure and large friction coefficient, shear crack initiation can also occur under the condition of high compressive confining pressure but low friction coefficient or that of low compressive confining pressure but high friction coefficient.

Assuming $\beta=20^{\circ}, \mu=0.5$ and $k=-3$, the $T_{x}$ and $T_{y}$ stresses are positive and negative, respectively. $\left|\tau_{r \theta}\right|_{\max } /\left(\sigma_{\theta}\right)_{\max }$ is 0.866 if the $T_{x}$ and $T_{y}$ stresses are neglected. This ratio decreases to 0.519 if only the $T_{x}$ stress is considered, which indicates that the positive $T_{x}$ stress inhibits shear crack initiation. However, when both the $T_{x}$ and $T_{y}$ stresses are included, $\left|\tau_{r \theta}\right|_{\max } /\left(\sigma_{\theta}\right)_{\max }$ increases to 2.228 , which indicates the possibility of the shear 
crack initiation being significantly increased. Because the $T_{y}$ stress is always negative if the crack is closed, the increase in the compressive confining pressure increases the absolute value of the negative $T_{y}$ stress and therefore increases the possibility of shear crack initiation. Summarizing, the discussion above demonstrates that the crack initiation type under combined tensile and compressive loading conditions remains tensile dominated when the compressive confining coefficient is small (i.e., $-1 \leq k \leq 0$ ). However, with increasing compressive confining pressure coefficient and friction coefficient, shear crack extension becomes possible from a crack with a small orientation angle. Moreover, the high compressive confining pressure and the large friction also result in the closing of the crack faces and the lower tendency for sliding along the crack faces, where shear failure is the only possible failure type.

Note that, in laboratory rock fracture experiments, artificial notches or cracks that are not real cracks are often created in rock specimens, and a gap often exists between the crack flanks. In this case, if the rock specimen is a hard rock and if the width of the notch is relatively large, the crack may extend before its closure under compressive loads. For this case where the $T_{y}$ stress is zero because the crack is in the open state even though it is subjected to compression-shear stresses. Moreover, because a Griffith crack is considered as a slit in theoretical studies, the parameter $K_{I}$ is zero as well. However, for an artificial crack, which may have a radius at the crack tip, Tirosh and Catz (1981) proposed a method for determining the parameter $K_{I}$. Therefore, the parameters $K_{I}$ and $T_{y}$ are set to zero when Eq. (8) is used to determine the fracture 
parameters for the fracture behavior of a pre-fabricated crack with no contact between the crack flanks in the laboratory rock fracture experiments.

\section{Conclusions}

In engineering practice, rock and rock mass are frequently subjected to combined tensile and compressive loads. Under such loading conditions, a pre-existing crack in rock may close or open depending on the orientation angle of the pre-existing crack and the confining pressure coefficient. Compared with the available analytical solutions for an angled crack in a plate subjected to far-field bi-axial load, the study on the growth characteristics of the angled crack under the combined tensile and compressive loading conditions reveals the following:

(1) If a combined tensile and compressive load is applied to a rock plate with an angled crack, there is a transitional crack orientation angle between the closed and open states of the crack, and the value of the transition angle depends on the compressive confining pressure coefficient but is independent of the friction coefficient. Moreover, there is a range of the crack orientation angle in which the effective shear stress on the crack surfaces is zero.

(2) If the tensile load dominates in the combined tensile and compressive loading condition (i.e., $-1<k \leq 0$ ), the crack initiation type remains tensile dominated in the rock plate with the angled crack, and the crack initiation angle is affected by the crack 
orientation angle and the compressive confining pressure coefficient. However, for a closed crack, the crack initiation angle also depends on the friction coefficient of the crack surfaces: the higher the friction coefficient, the larger the crack initiation angle. Furthermore, the $T$-stress is very important in determining the crack growth direction, especially for a closed crack with a high friction coefficient. By comparing this study with experimental tests in the literature, it is concluded that both the crack initiation angle and the crack growth direction predicted by this study agree well with those from the experimental tests.

(3) For a rock plate with an angled crack under the combined tensile and compressive loading conditions, shear crack initiation can only occur in a small range of crack orientation angles. The positive $T_{x}$ stress inhibits shear crack initiation, and the negative $T_{y}$ stress increases the possibility of shear crack initiation.

\section{Acknowledgment}

This project was financially supported by the National Basic Research Program of China (973 Program) (2014CB047100) and the National Natural Science Foundation of China (51474046, U1562103), which are greatly appreciated. 


\section{References}

Aliha, M.R.M., and Ayatollahi, M.R. 2009. Brittle fracture evaluation of a fine grain cement mortar in combined tensile-shear deformation. Fatigue Fract Eng M 32(12): 987-994.

Aliha, M.R.M., and Ayatollahi, M.R. 2013. Two-parameter fracture analysis of SCB rock specimen under mixed mode loading. Eng Fract Mech 103: 115-123.

Aliha, M.R.M., Ayatollahi, M.R., and Akbardoost, J. 2012. Typical upper boundlower bound mixed mode fracture resistance envelopes for rock material. Rock Mech Rock Eng 45(1): 65-74.

Aliha, M.R.M., Ayatollahi, M.R., and Pakzad, R. 2008. Brittle fracture analysis using a ring-shape specimen containing two angled cracks. Int J Fracture 153(1): 63-68.

Aliha, M.R.M., and Saghafi, H. 2013. The effects of thickness and Poisson's ratio on 3D mixed-mode fracture. Eng Fract Mech 98: 15-28.

Amarasiri, A.L., Costa, S., and Kodikara, J.K. 2011. Determination of cohesive properties for mode I fracture from compacted clay beams. Can Geotech J 48(8): 1163-1173.

Ayatollahi, M.R., and Aliha, M.R.M. 2007. Fracture toughness study for a brittle rock subjected to mixed mode I/II loading. Int J Rock Mech Min 44(4): 617-624.

Ayatollahi, M.R., and Aliha, M.R.M. 2008. On the use of Brazilian disc specimen for calculating mixed mode I-II fracture toughness of rock materials. Eng Fract Mech 75(16): 4631-4641.

Ayatollahi, M.R., Pavier, M.J., and Smith, D.J. 1998. Determination of T-stress from finite element analysis for mode I and mixed mode I/II loading. Int J Fracture 91(3): 283-298.

Ayatollahi, M.R., Pavier, M.J., and Smith, D.J. 2002a. Mode I cracks subjected to large T-stresses. Int J Fracture 117(2): 159-174.

Ayatollahi, M.R., Smith, D.J., and Pavier, M.J. 2002b. Crack-tip Constraint in mode II deformation. Int J Fracture 113(2): 153-173.

Bakuckas, J.G., Tan, T.M., Lau, A.C.W., and Awerbuch, J. 1993. A numerical model for predicting crack path and modes of damage in unidirectional metal matrix composites. J Reinf Plast Comp 12(3): 341-358.

Bobet, A. 2000. The initiation of secondary cracks in compression. Eng Fract Mech 66(2): 187-219. 
Bobet, A., and Einstein, H.H. 1998. Numerical modeling of fracture coalescence in a model rock material. Int J Fracture 92(3): 221-252.

Bordi, V., Dorier, C., and Villechaise, B. 1998. A finite element analysis of crack initiation and propagation in a notched disk submitted to rolling contact fatigue. Journal of tribology 120(3): 436-441.

Bouissou, S., Petit, J.P., and Barquins, M. 1998. Experimental evidence of contact loss during stick-slip: possible implications for seismic behaviour. Tectonophysics 295(3): 341-350.

Broberg, K.B. 1987. On crack paths. Eng Fract Mech 28(5): 663-679.

Castro, J., Cicero, S., and Sagaseta, C. 2016. A Criterion for Brittle Failure of Rocks Using the Theory of Critical Distances. Rock Mech Rock Eng 49(1): 63-77.

Chang, K.J. 1981. Further studies of the maximum stress criterion on the angled crack problem. Eng Fract Mech 14(1): 125-142.

Chang, K.J. 1982. A further examination on the application of the strain energy density theory to the angled crack problem. Journal of Applied Mechanics 49(2): 377-382.

Chao, Y.J., and Liu, S. 1997. On the failure of cracks under mixed-mode loads. Int J Fracture 87(3): 201-223.

Cotterell, B. 1966. Notes on the paths and stability of cracks. Int J Fract Mech 2(3): 526-533

Dieterich, J.H. 1981. Potential for geophysical experiments in large scale tests. Geophys Res Lett 8(7): 653-656.

Eftis, J., and Subramonian, N. 1978. The inclined crack under biaxial load. Eng Fract Mech 10(1): 43-67.

Erarslan, N., and Williams, D.J. 2013. Mixed-mode fracturing of rocks under static and cyclic loading. Rock Mech Rock Eng 46(5): 1035-1052.

Erdogan, F., and Sih, G.C. 1963. On the Crack Extension in Plates under Plane Loading and Transverse Shear. Journal of Basic Engineering-ASME 85: 519-527.

Finnie, I., and Saith, A. 1973. A note on the angled crack problem and the directional stability of cracks. Int J Fracture 9(4): 484-486.

Funatsu, T., Kuruppu, M., and Matsui, K. 2014. Effects of temperature and confining pressure on mixed-mode (I-II) and mode II fracture toughness of Kimachi sandstone. Int J Rock Mech Min 67: 1-8. 
Ge, Z., Wang, H., Wang, Y., and Hu, X. 2014. Evaluating fatigue behavior of asphalt mixtures under alternate tension-compression loading model using new alternate biaxial splitting method. Constr Build Mater 54: 106-112.

Golos, K., and Wasiluk, B. 2000. Role of plastic zone in crack growth direction criterion under mixed mode loading. Int J Fracture 102(4): 341-353.

Gupta, M., Alderliesten, R.C., and Benedictus, R. 2015. A review of T-stress and its effects in fracture mechanics. Eng Fract Mech 134: 218-241.

Irwin, G.R. 1958. Handbook of Physics. Springer Verlag, Berlin. pp. 551-590.

Isaksson, P., and Ståhle, P. 2002. Prediction of shear crack growth direction under compressive loading and plane strain conditions. Int J Fracture 113(2): 175-194.

Jaeger, J.C., and Cook, N.G.W. 1979. Fundamentals of Rock Mechanics. Chapman and Hall, London.

Kannusamy, R., and Ramesh, K. 2014. Analytical Prediction of Fatigue Crack Growth Behavior Under Biaxial Loadings. Journal of Pressure Vessel Technology 136(2): 021204-021204.

Khan, S.M.A., and Khraisheh, M.K. 2000. Analysis of mixed mode crack initiation angles under various loading conditions. Eng Fract Mech 67(5): 397-419.

Kim, J.H., and Paulino, G.H. 2003. T-stress, mixed-mode stress intensity factors, and crack initiation angles in functionally graded materials: a unified approach using the interaction integral method. Comput Method Appl M 192(11): 1463-1494.

Kong, X.M., Schlüter, N., and Dahl, W. 1995. Effect of triaxial stress on mixed-mode fracture. Eng Fract Mech 52(2): 379-388.

Labuz, J.F., Riedel, J.J., and Dai, S. 2006. Shear fracture in sandstone under plane-strain compression. Eng Fract Mech 73(6): 820-828.

Larsson, S.G., and Carlsson, A.J. 1973. Influence of non-singular stress terms and specimen geometry on small-scale yielding at crack tips in elastic-plastic materials. J Mech Phys Solids 21(4): 263-277.

Lee, S., and Ravichandran, G. 2003. Crack initiation in brittle solids under multiaxial compression. Eng Fract Mech 70(13): 1645-1658.

Leevers, P.S., and Radon, J.C. 1982. Inherent stress biaxiality in various fracture specimen geometries. Int J Fracture 19(4): 311-325. doi: 10.1007/BF00012486.

Li, X.F., Liu, G.L., and Lee, K.Y. 2009. Effects of T-stresses on fracture initiation for a closed crack in compression with frictional crack faces. Int J Fracture 160(1): 19-30. 
Liebowitz, H., Lee, J.D., and Eftis, J. 1978. Biaxial load effects in fracture mechanics. Eng Fract Mech 10(2): 315-335.

Ling, K.H. 1980. On inclined crack under mixed mode loading. The University of Hong Kong, Hong Kong. p. 160.

Maiti, S.K., and Smith, R.A. 1983. Comparison of the criteria for mixed mode brittle fracture based on the preinstability stress-strain field Part I: Slit and elliptical cracks under uniaxial tensile loading. Int J Fracture 23(4): 281-295.

Martel, S.J., and Pollard, D.D. 1989. Mechanics of slip and fracture along small faults and simple strike-slip fault zones in granitic rock. Journal of Geophysical Research: Solid Earth (1978-2012) 94(B7): 9417-9428.

Meek, C., and Ainsworth, R.A. 2015. The effects of load biaxiality and plate length on the limit load of a centre-cracked plate. 147: 306-317.

Melin, S. 1986. When does a crack grow under mode II conditions? Int J Fracture 30(2): 103-114. doi: 10.1007/BF00034020.

Mirlohi, S., and Aliha, M. 2013. Crack growth path prediction for the angled cracked plate using higher order terms of Williams series expansion. Engineering Solid Mechanics 1(3): 77-84.

Mirsayar, M.M. 2014. On fracture of kinked interface cracks-The role of T-stress. Materials and Design 61: 117-123.

Mróz, K.P., and Mróz, Z. 2010. On crack path evolution rules. Eng Fract Mech 77(11): 1781-1807.

Otsuka, A., Mori, K., and Miyata, T. 1975. The condition of fatigue crack growth in mixed mode condition. Eng Fract Mech 7(3): 429-439.

Palmer, A.C., and Rice, J.R. 1973. The growth of slip surfaces in the progressive failure of over-consolidated clay. In Proceedings of the Royal Society of London A: Mathematical, Physical and Engineering Sciences. The Royal Society. pp. 527-548.

Papadopoulos, G.A. 1988. Crack initiation under biaxial loading. Eng Fract Mech 29(5): 585-598.

Park, C.H., and Bobet, A. 2009. Crack coalescence in specimens with open and closed flaws: A comparison. Int J Rock Mech Min 46(5): 819-829.

Rice, J.R. 1967. The mechanics of crack tip deformation and extension by fatigue. In Fatigue Crack Propagation, ASTM STP 415, Philadelphia. pp. 247-311.

Roychowdhury, S., and Dodds, R.H. 2004. Effect of T-stress on fatigue crack closure in 3-D small-scale yielding. Int J Solids Struct 41(9): 2581-2606. 
Schmidt, R.A. 1981. A microcrack model and its significance to hydraulic fracturing and fracture toughness testing. Int J Rock Mech Min Geom Abs 81(5): 85.

Seweryn, A., and Mróz, Z. 1995. A non-local stress failure condition for structural elements under multiaxial loading. Eng Fract Mech 51(6): 955-973.

Shamoto, E., and Altıntas, Y. 1999. Prediction of shear angle in oblique cutting with maximum shear stress and minimum energy principles. Journal of manufacturing science and engineering 121(3): 399-407.

Shetty, D.K., Rosenfield, A.R., and Duckworth, W.H. 1987. Mixed-mode fracture in biaxial stress state: Application of the diametral-compression (Brazilian disk) test. Eng Fract Mech 26(6): 825-840.

Shlyannikov, V.N. 2013. T-stress for crack paths in test specimens subject to mixed mode loading. Eng Fract Mech 108: 3-18.

Smith, D.J., Ayatollahi, M.R., and Pavier, M.J. 2001. The role of T-stress in brittle fracture for linear elastic materials under mixed-mode loading. Fatigue Fract Eng $M$ 24(2): 137-150.

Smith, D.J., Ayatollahi, M.R., and Pavier, M.J. 2006. On the consequences of T-stress in elastic brittle fracture. Proceedings of the Royal Society A: Mathematical, Physical and Engineering Science 462(2072): 2415-2437.

Theocaris, P.S., and Michopoulos, J.G. 1983. A closed-form solution of a slant crack under biaxial loading. Eng Fract Mech 17(2): 97-123.

Tirosh, J., and Catz, E. 1981. Mixed-mode fracture angle and fracture locus of materials subjected to compressive loading. Eng Fract Mech 14(1): 27-38.

Ueda, Y., Ikeda, K., Yao, T., and Aoki, M. 1983. Characteristics of brittle fracture under general combined modes including those under bi-axial tensile loads. Eng Fract Mech 18(6): 1131-1158.

Vásárhelyi, B., and Bobet, A. 2000. Modeling of crack initiation, propagation and coalescence in uniaxial compression. Rock Mech Rock Eng 33(2): 119-139.

Williams, J.G., and Ewing, P.D. 1972. Fracture under complex stress-The angled crack problem. Int J Fracture 8(4): 441-446. doi: 10.1007/BF00191106.

Williams, M.L. 1957. On the stress distribution at the base of a stationary crack. Journal of Applied Mechanics 24(1): 109-114.

Wong, L.N.Y., and Einstein, H.H. 2009. Systematic evaluation of cracking behavior in specimens containing single flaws under uniaxial compression. Int J Rock Mech Min 46(2): 239-249. 
Wong, R.H.C., and Chau, K.T. 1998. Crack coalescence in a rock-like material containing two cracks. Int J Rock Mech Min 35(2): 147-164.

Wu, Z., and Wong, L.N.Y. 2012. Frictional crack initiation and propagation analysis using the numerical manifold method. Comput Geotech 39: 38-53.

Wu, Z., and Wong, L.N.Y. 2013. Modeling cracking behavior of rock mass containing inclusions using the enriched numerical manifold method. Eng Geol 462: 1-13.

Xeidakis, G.S., Samaras, I.S., Zacharopoulos, D.A., and Papakaliatakis, G.E. 1997. Trajectories of unstably growing cracks in mixed mode I-II loading of marble beams. Rock Mech Rock Eng 30(1): 19-33.

Zanganeh, M., Tomlinson, R.A., and Yates, J.R. 2008. T-stress determination using thermoelastic stress analysis. The Journal of Strain Analysis for Engineering Design 43(6): 529-537.

Zeng, Z.J., and Dai, S.H. 1994. Stress intensity factors for an inclined surface crack under biaxial stress state. Eng Fract Mech 47(2): 281-289. 


\section{FIGURE CAPTIONS}

Fig. 1 Schematic sketch of the pre-existing crack subjected to external compression and inner pressure.

Fig. 2 Schematic sketch of the pre-existing crack under combined tensile and compressive loading conditions.

Fig. 3 The Cartesian and polar coordinate systems .

Fig. 4 Schematic sketch of the non-singular stress of a closed crack.

Fig. 5 (a) Relationship between the normalized normal stress on the crack face and the crack orientation angle, and (b) relationship between the crack orientation angle and the confining pressure coefficient when $\sigma_{n}=0$.

Fig. 6 Relationship between the normalized effective shear stress on the crack faces and the crack orientation angle: (a) $\mu=0.2$ and (b) $\mu=0.5$

Fig. 7 Effect of the confining pressure coefficient on the distribution of $\sigma_{\theta}$ and $\tau_{r \theta}$ the crack tip when $\beta=30^{\circ}$ and $\mu=0.5$ with and without the $T$-stresses taken into account

Fig. 8 Effect of the crack orientation angle on the distribution of $\sigma_{\theta}$ and $\tau_{r \theta}$ around the crack tip when $k=-0.5$ and $\mu=0.5$ with and without the $T$-stresses taken into account

Fig. 9 Effect of the friction coefficient on the distribution of $\sigma_{\theta}$ and $\tau_{r \theta}$ around the crack tip when $\beta=30^{\circ}$ with and without the $T$-stresses taken into account

Fig. 10 Relationship between the crack initiation angle and the crack orientation angle for the pre-existing crack under far-field uniaxial tension and its comparison with the experimental data in literatures (Ling 1980; Ueda et al. 1983).

Fig. 11 Relationship between the crack initiation angle and the crack orientation angle for the pre-existing crack under the far-field combined tensile and compressive loads and its comparison with the experimental data in literatures (Ling 1980).

Fig. 12 Relationship between the crack initiation stress and the crack orientation angle for the pre-existing crack under the far-field combined tensile and compressive loads and its comparison with the experimental data in literatures (Ling 1980).

Fig. 13 (a) Relationship between the ratio of $\left|\tau_{\mathrm{r} \theta}\right|_{\max }$ and $\left(\sigma_{\theta}\right)_{\max }$ and the confining pressure coefficient when $\beta=25^{\circ}$ and $\mu=0.2$ or $\mu=0.5$, (b) Relationship between the crack orientation angle $\beta$ and the confining pressure coefficient $k$ when $\left|\tau_{r \theta}\right|_{\max } /\left(\sigma_{\theta}\right)_{\max }=2$ and $\mu=0.5$, and (c) Relationship between the confining pressure coefficient $k$ and the critical friction coefficient $\mu$ which leads to shear crack initiation. 


\section{FIGURES}

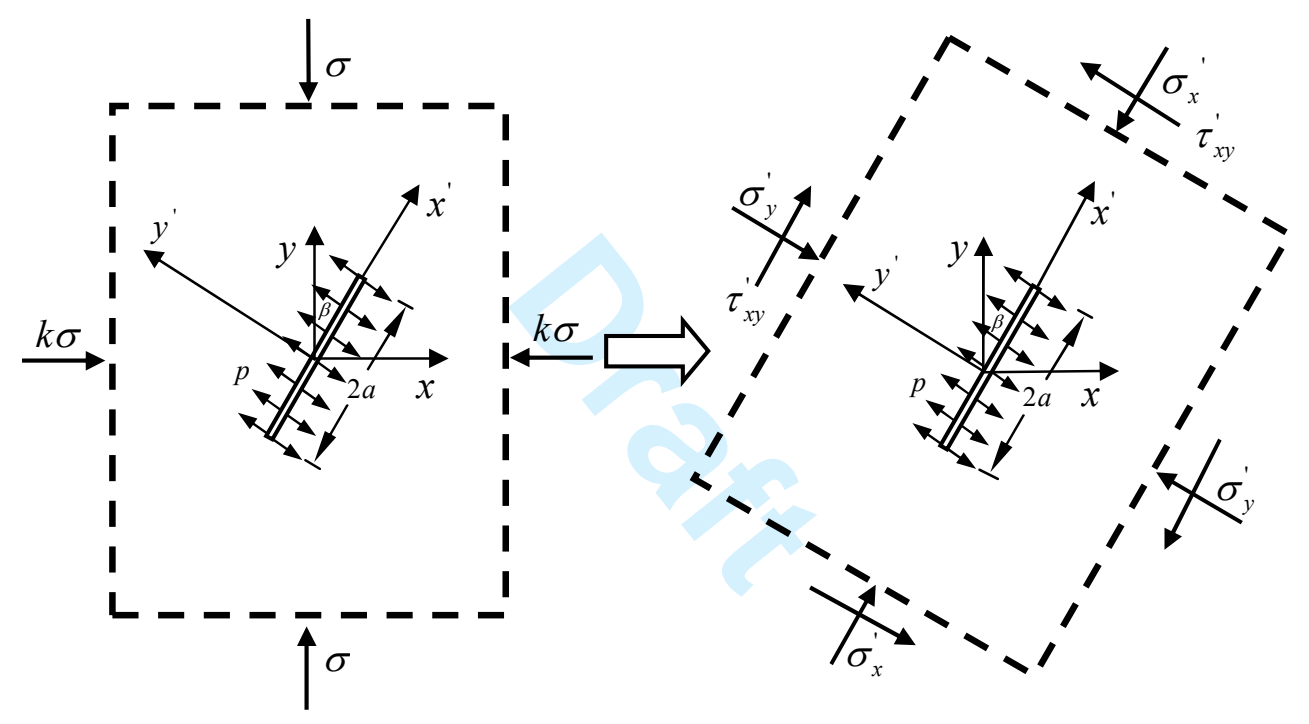

Fig. 1 


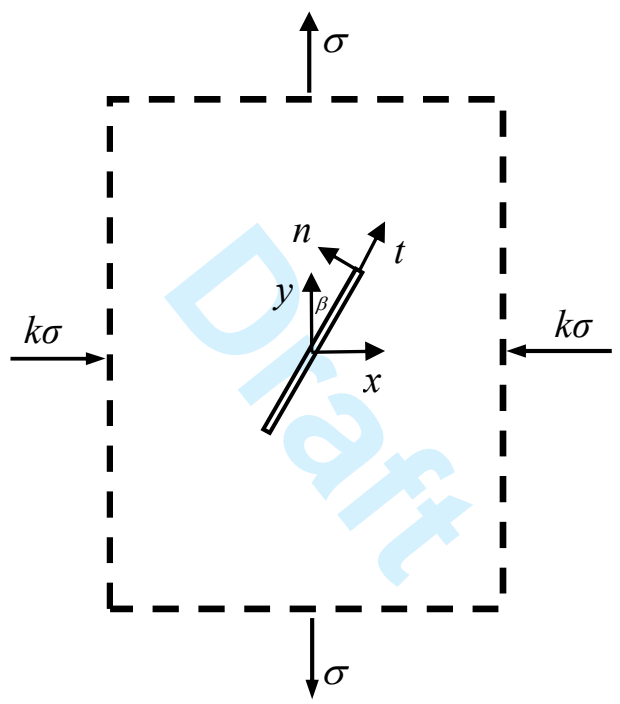

Fig. 2 


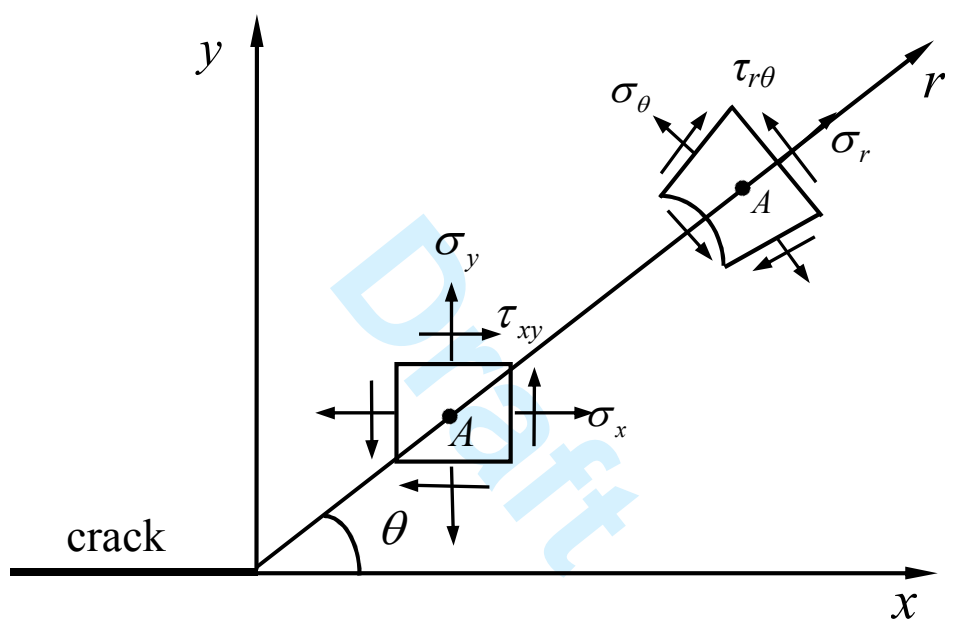

Fig. 3 


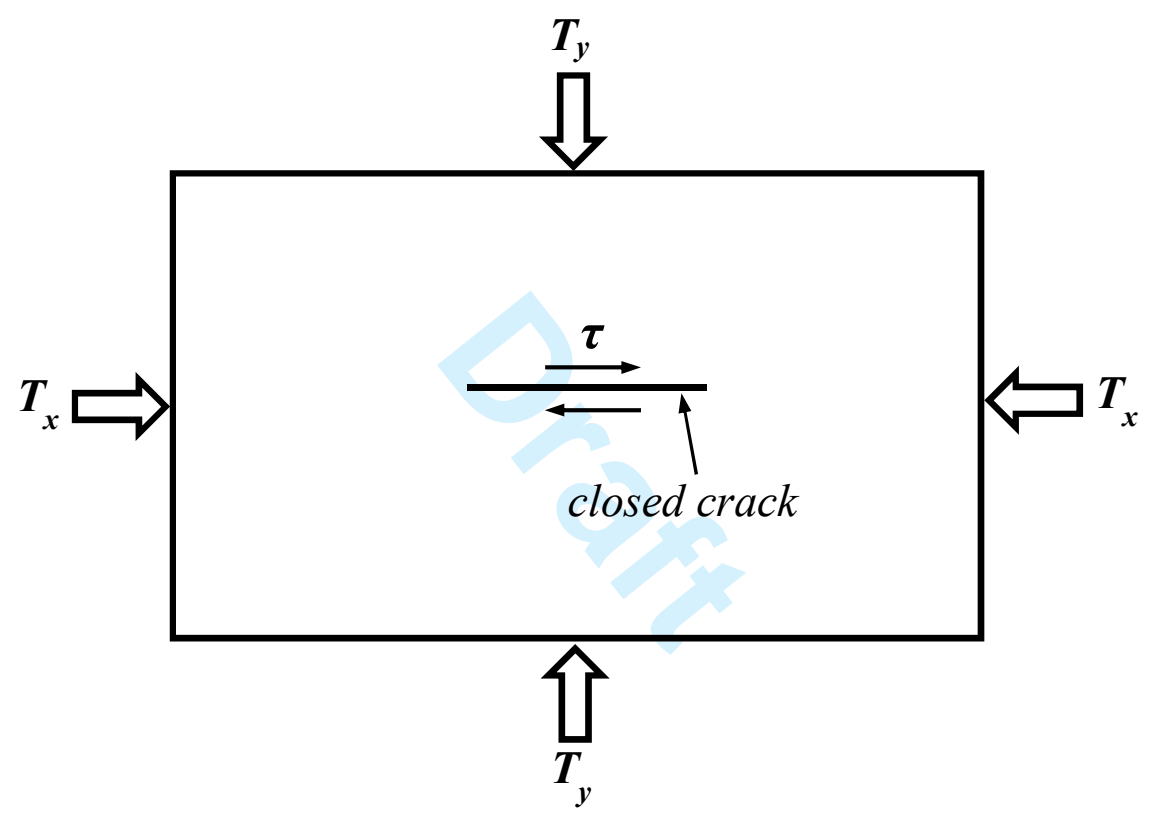

Fig. 4 

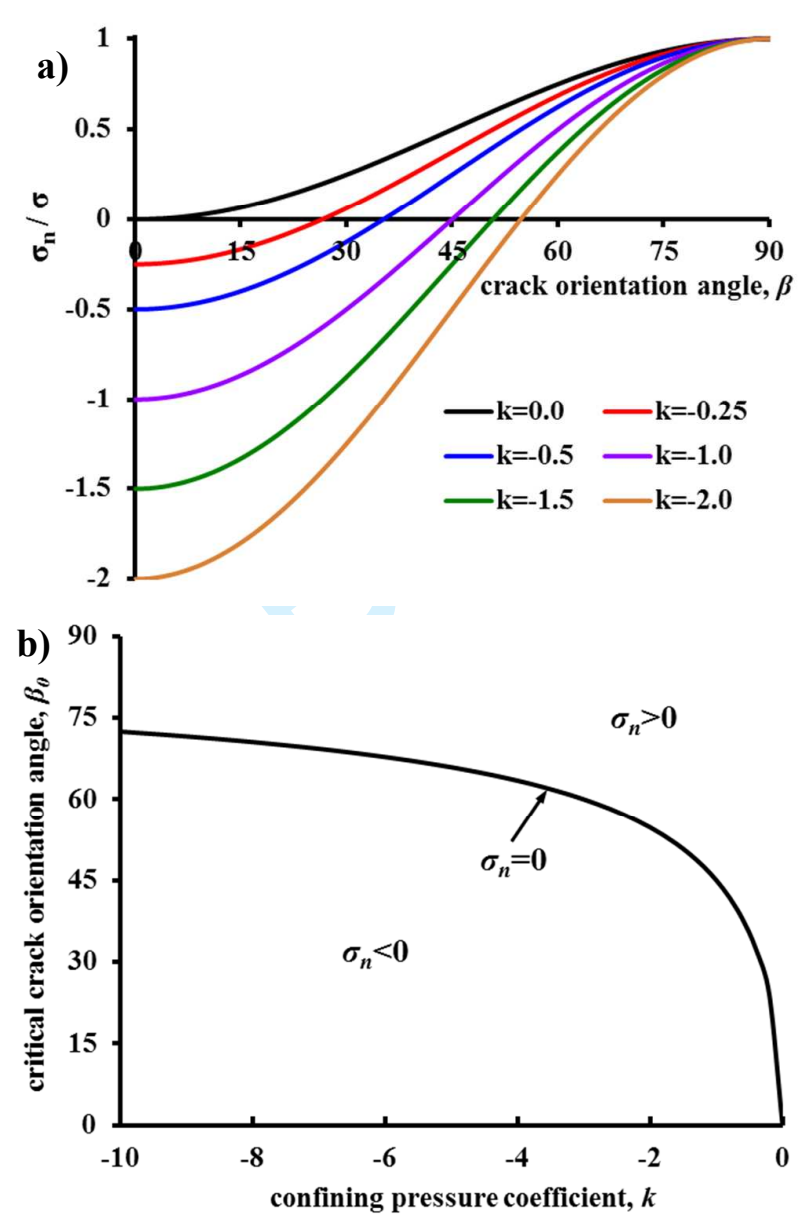

Fig. 5 

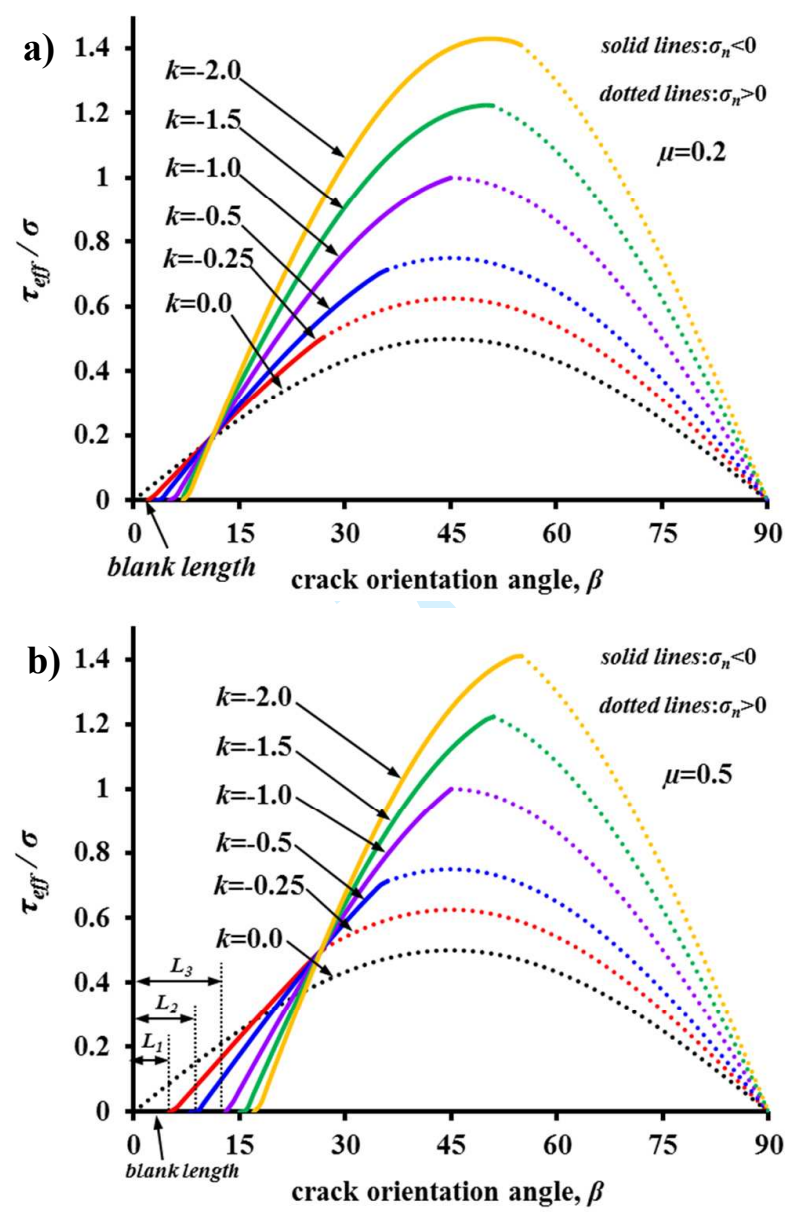

Fig. 6 

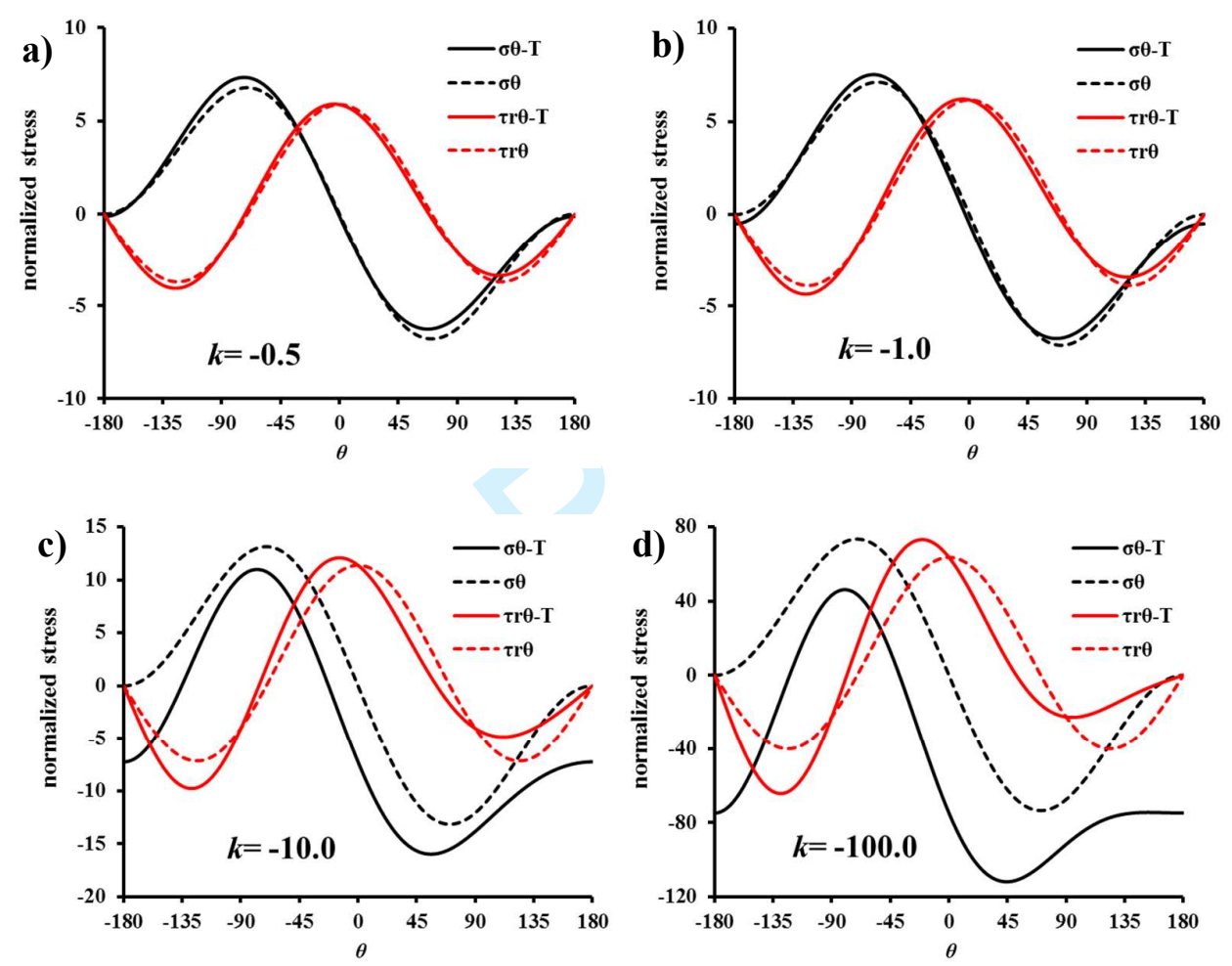

Fig. 7 

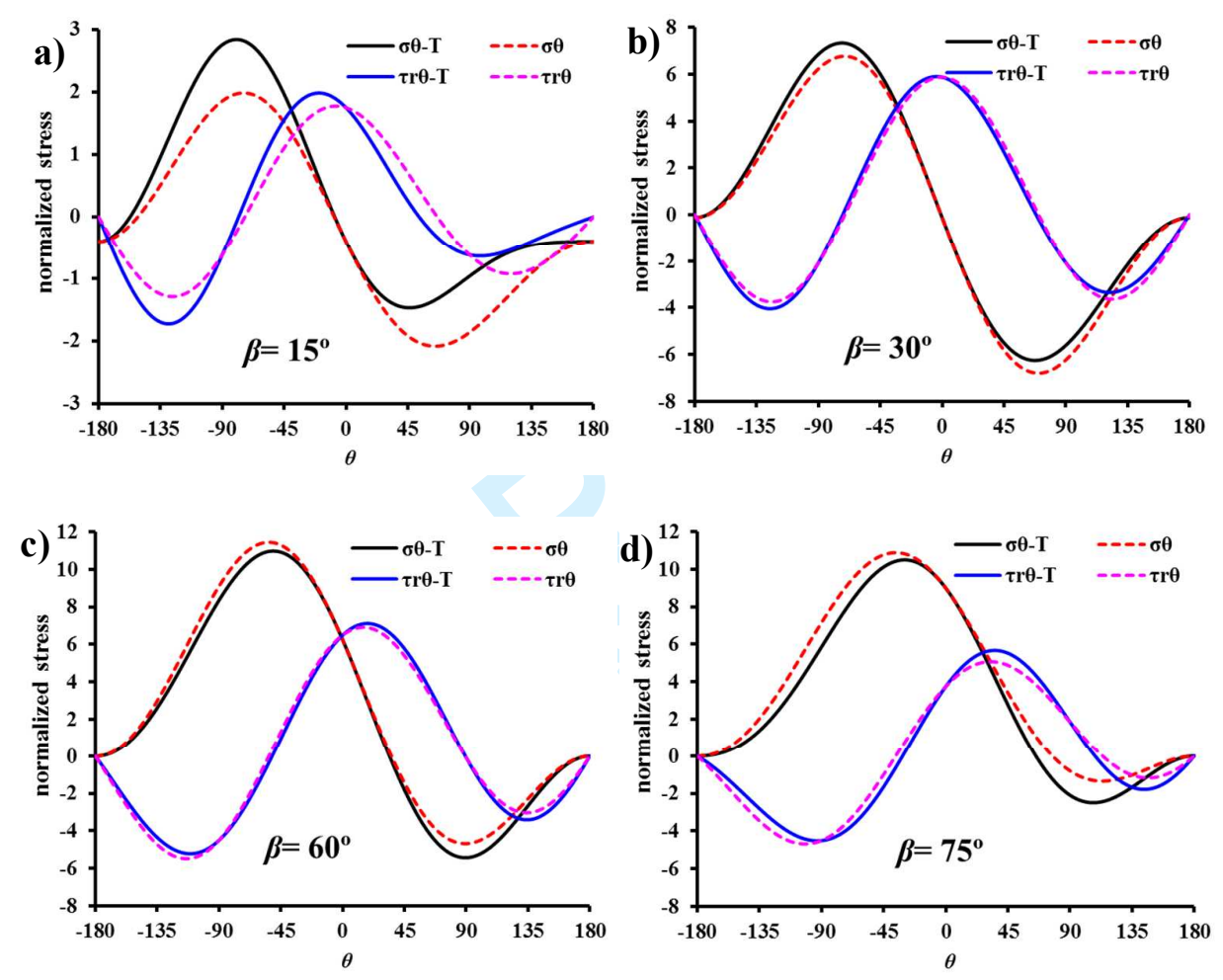

Fig. 8 

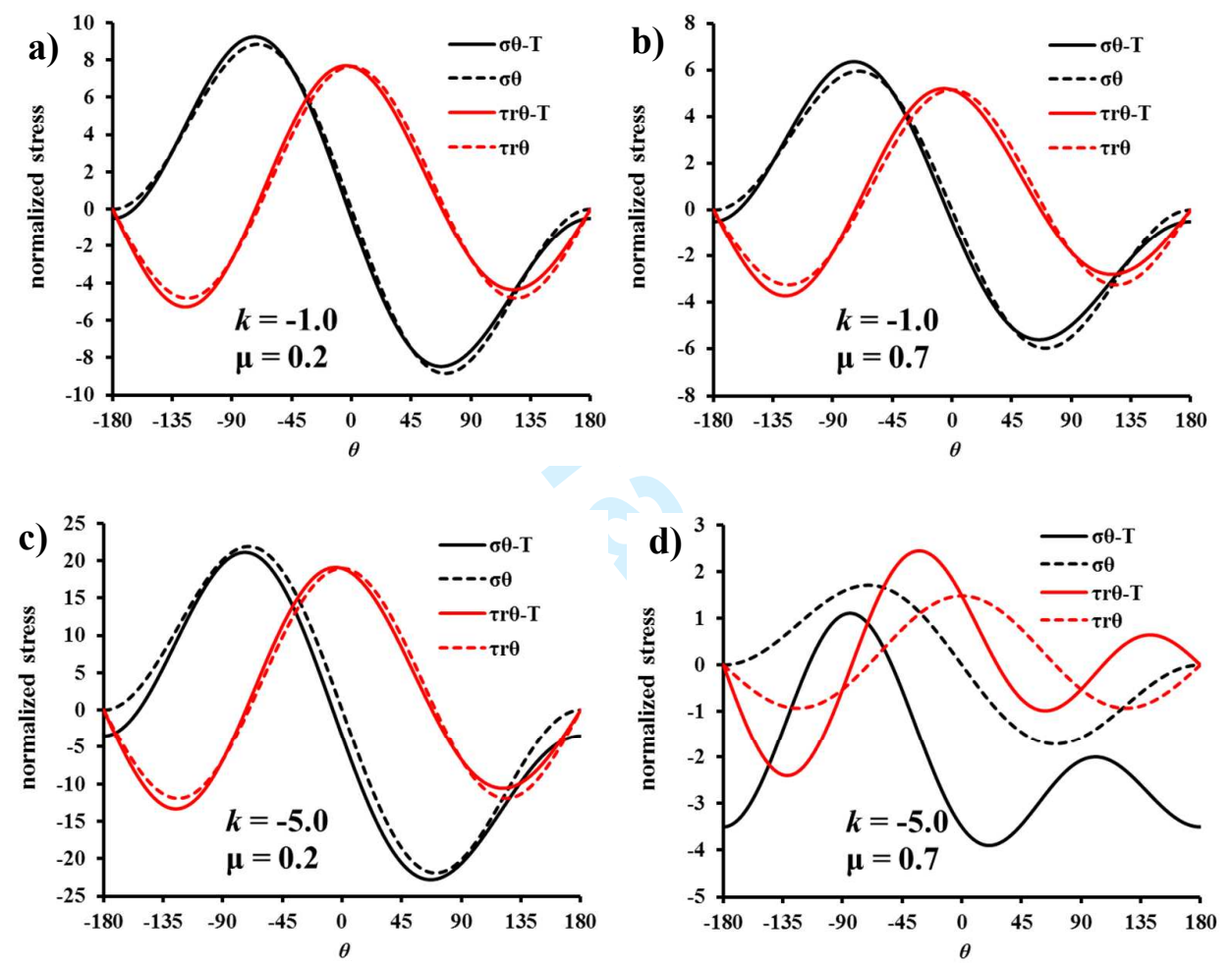

Fig. 9 


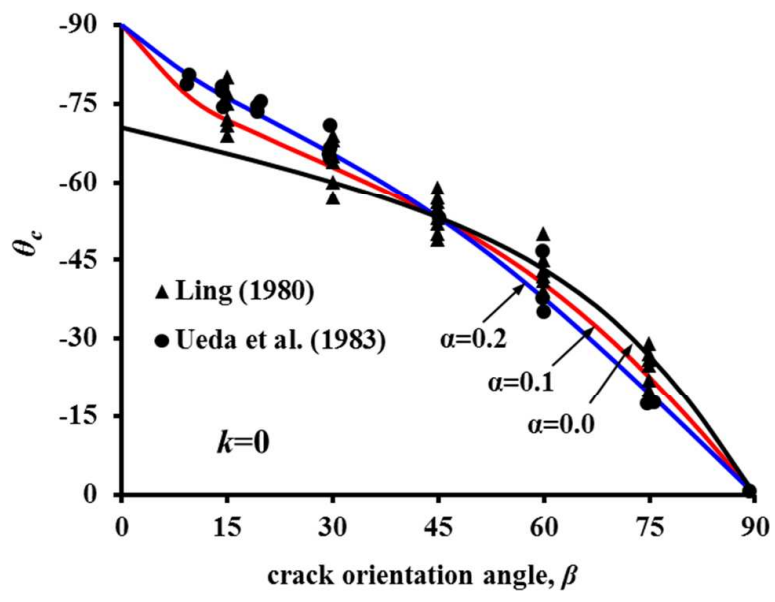

Fig. 10 

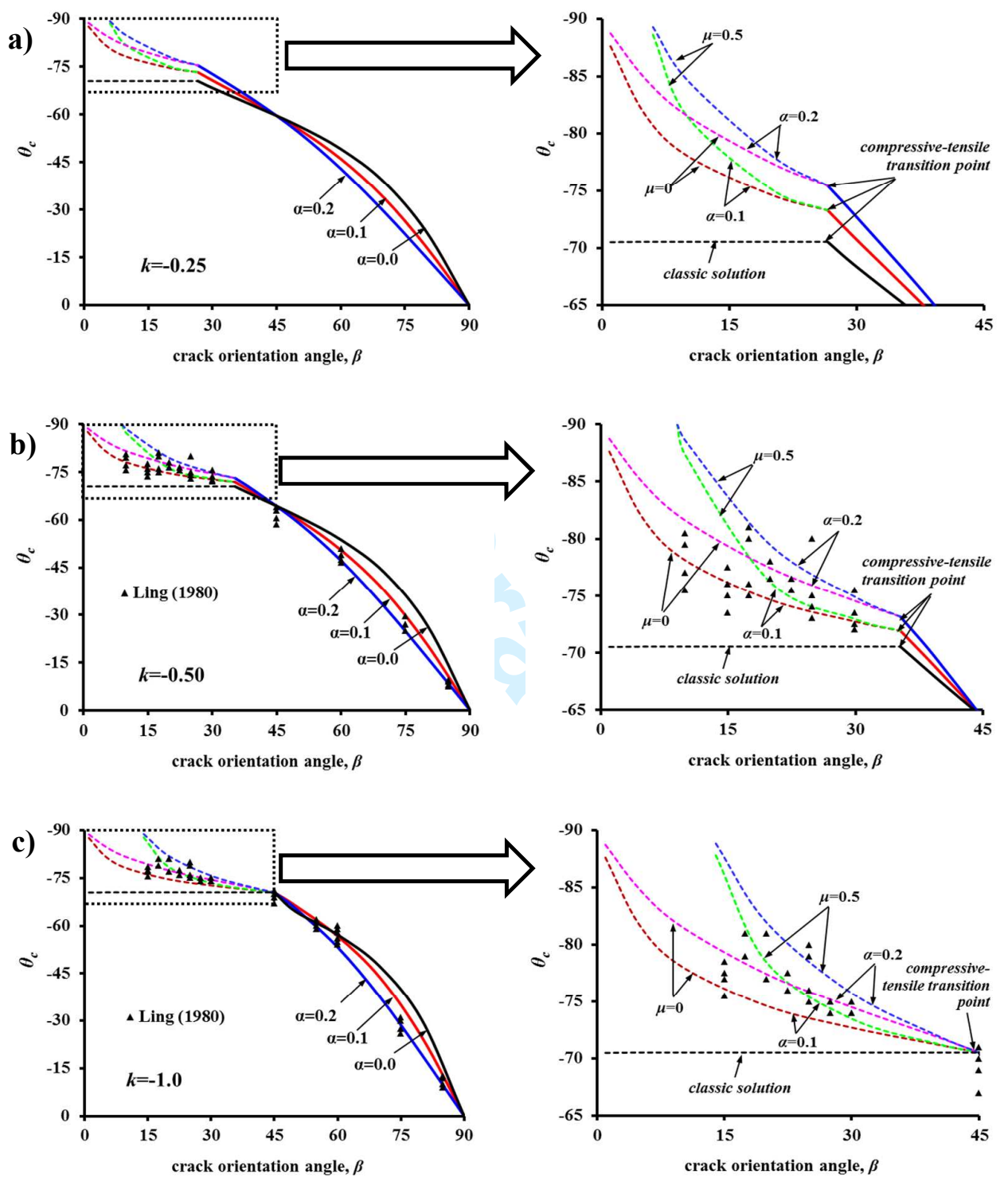

Fig. 11 

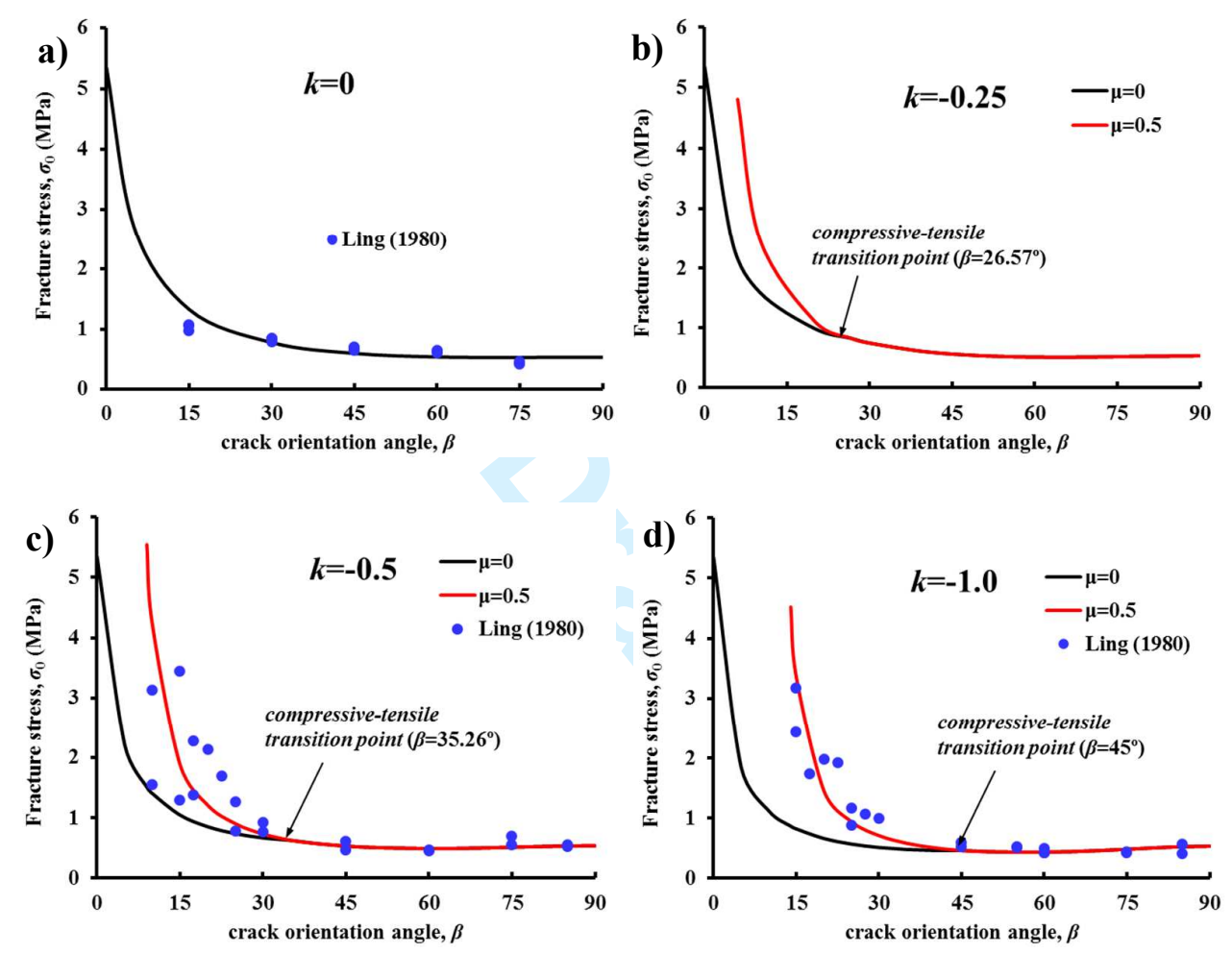

Fig. 12 


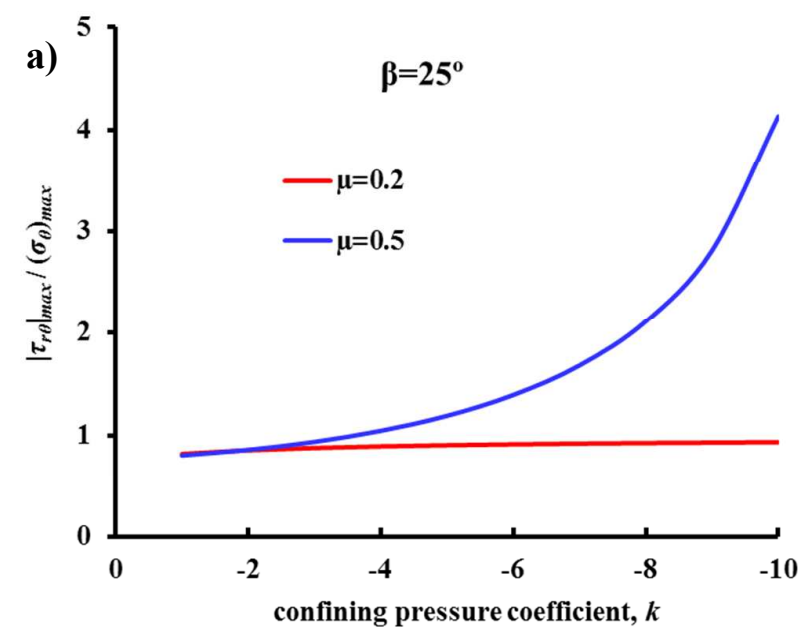

(c)
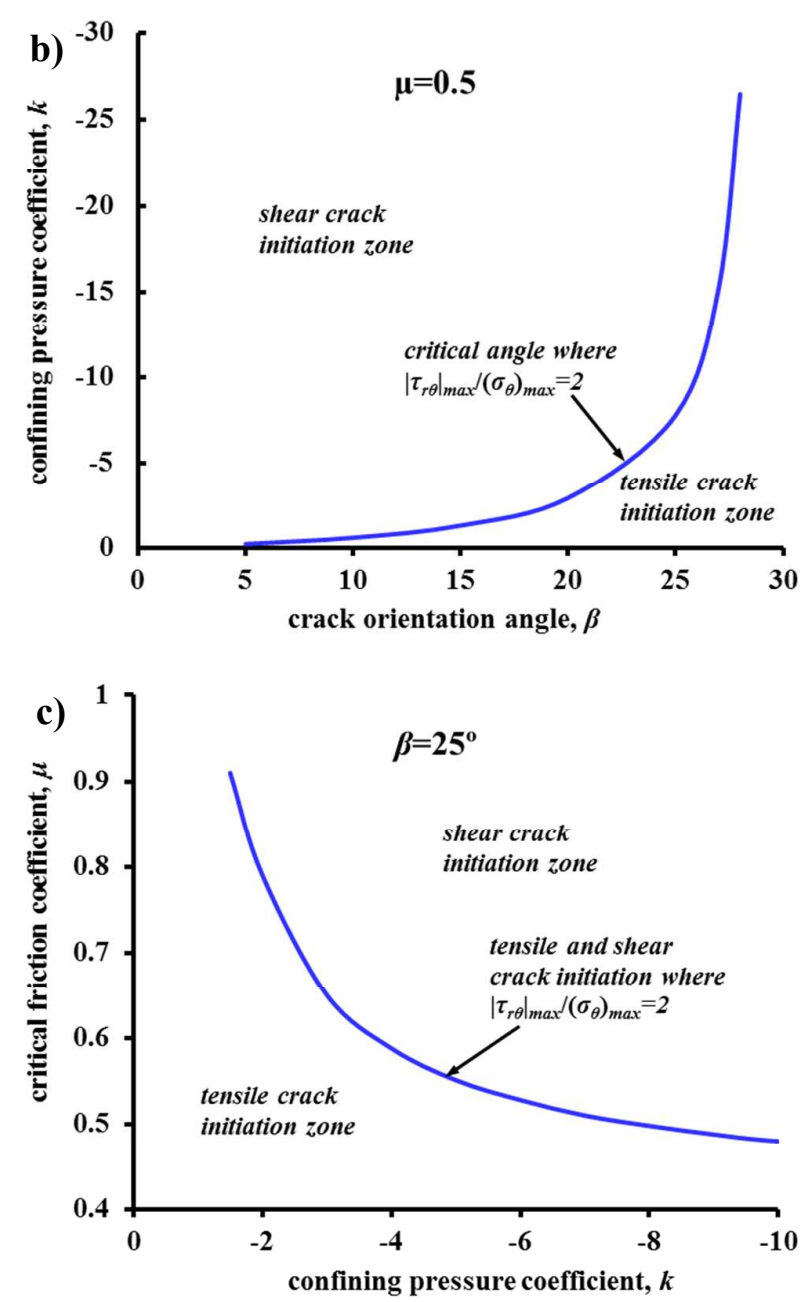

Fig. 13 